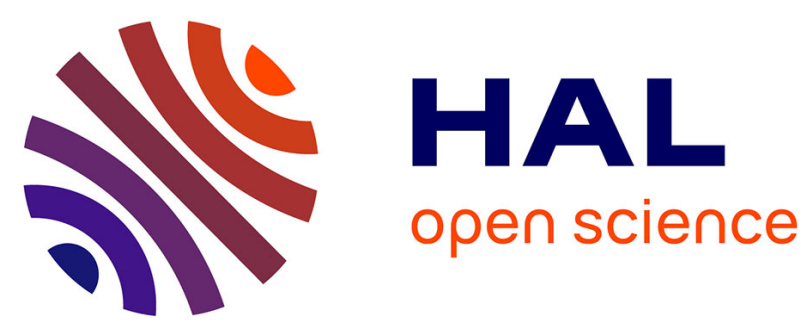

\title{
The use of encapsulation as a proposed solution to avoid problems encountered with conventional materials in powder form Application in methylene blue removal from aqueous solutions
}

\author{
Abderraouf Guediri, A. Bouguettoucha, Derradji Chebli, A. Amrane
}

\section{To cite this version:}

Abderraouf Guediri, A. Bouguettoucha, Derradji Chebli, A. Amrane. The use of encapsulation as a proposed solution to avoid problems encountered with conventional materials in powder form Application in methylene blue removal from aqueous solutions. Journal of Molecular Liquids, 2020, 316, pp.113841. 10.1016/j.molliq.2020.113841 . hal-02931998

\author{
HAL Id: hal-02931998 \\ https://hal.science/hal-02931998
}

Submitted on 26 Nov 2020

HAL is a multi-disciplinary open access archive for the deposit and dissemination of scientific research documents, whether they are published or not. The documents may come from teaching and research institutions in France or abroad, or from public or private research centers.
L'archive ouverte pluridisciplinaire HAL, est destinée au dépôt et à la diffusion de documents scientifiques de niveau recherche, publiés ou non, émanant des établissements d'enseignement et de recherche français ou étrangers, des laboratoires publics ou privés. 


\section{The use of encapsulation as a proposed solution to avoid problems}

\section{encountered with conventional materials in powder form: application in methylene blue removal from aqueous solutions}

Abderraouf Guediri ${ }^{1}$, Abdallah Bouguettoucha ${ }^{1 *}$, Derradji Chebli ${ }^{1}$, Abdeltif Amrane $^{2}$

${ }^{1}$ Département de Génie des Procédés, Laboratoire de Génie des Procédés Chimiques, Faculté de Technologie, Université Ferhat Abbas, Sétif-1, 19000 Sétif, Algeria

$$
\text { Tel. +213369251 21; Fax: +21336925121; }
$$

${ }^{2}$ Univ Rennes, Ecole Nationale Supérieure de Chimie de Rennes, CNRS, ISCR - UMR6226, F-35000 Rennes, France. E-mail: abdeltif.amrane@univ-rennes1.fr

* Corresponding auteur mail: abdallah.bouguettoucha@univ-setif.dz

Co-authors e-mail: (Abderraouf Guediri) abderraoufguediri@hotmail.com

(Derradji Chebli),derradji_chebli@yahoo.fr

(Abdeltif Amrane), abdeltif.amrane@univ-rennes1.fr

\section{Abstract}

The Ziziphus jujuba stones chemically modified with orthophosphoric acid (PZJS), then encapsulated with sodium alginate (BZJS1 and BZJS2) were used for organic dye adsorption. In this context, the basic dye methylene blue (MB) was chosen as a test molecule. The characteristics of the prepared beads were examined by different characterization techniques, such as Fourier transform infrared spectroscopy (FTIR), scanning electron microscopy (SEM), energy dispersive X-ray diffraction (EDX), X-ray fluorescence (XRF), Thermogravimetric analysis (TGA) and Brunauer-Emmett-Teller method (BET) with nitrogen adsorptiondesorption isotherm at $77^{\circ} \mathrm{K}$. In a batch system, initial $\mathrm{pH}(2-12)$, temperature $(10,25,30$ and 
$\left.40{ }^{\circ} \mathrm{C}\right)$, initial concentration $(50-200 \mathrm{mg} / \mathrm{L})$, contact time, salt and organic compound effects were studied. The obtained results showed that the maximum MB adsorption amounts were $737.13 \mathrm{mg} / \mathrm{g}$ and $660.12 \mathrm{mg} / \mathrm{g}$ onto BZJS1 and BZJS2 at ambient temperature respectively, showing that the prepared materials are more efficient than most of the other adsorbents. Moreover, experimental data modeling showed that the adsorption process followed the Redlich-Peterson model. Regarding kinetics modeling, pseudo-first-order (PFO), pseudosecond-order and Pseudo-nth order models were used to correlate experimental data, demonstrating that a mass transfer equation (PFO) could describe MB adsorption. Thermodynamic Parameters were also evaluated, demonstrating that the MB adsorption process was achievable, spontaneous and exothermic. The regeneration study showed that both of the beads had excellent adsorption efficiency even at the sixth cycle for the two beads, 92.01 and 82.88 for BZJS1 and BZJS2, respectively. From this and in view of a future implementation at industrial scale, encapsulation by sodium alginate polymer can be therefore promisingly proposed as a solution to avoid the problems of conventional materials in powder form, such as the difficulty of regeneration, performances and mass loss during the recovery step of the powder from the medium.

Keywords: Adsorption, methylene blue, Ziziphus jujuba, alginate, encapsulation, regeneration. 


\section{Nomenclature}

A Constant of intra particular diffusion.

BZJS Beads of Ziziphus jujuba stones.

BZJS1 Beads of Ziziphus jujuba stones with a PZJS-alginate ratio equal to 1.

BZJS2 Beads of Ziziphus jujuba stones with a PZJS-alginate ratio equal to 2.

Co $\quad$ MB initial concentration $(\mathrm{mg} / \mathrm{L})$.

$\mathbf{C}_{\mathbf{e}} \quad$ The equilibrium concentration $(\mathrm{mg} / \mathrm{L})$.

$\mathbf{C}_{\mathbf{t}} \quad$ MB concentration after time $\mathrm{t}(\mathrm{mg} / \mathrm{L})$.

$\mathbf{E}_{\mathbf{R}} \quad$ Regeneration efficiency (\%).

$\mathbf{K}_{\mathbf{1}} \quad$ Pseudo first order (PFO) rate constant $\left(\mathrm{min}^{-1}\right)$.

$\mathbf{K}_{2} \quad$ Pseudo second-order (PSO) adsorption rate constant (g/(mg min)).

Kn Rate constant of Pseudo nth order $\left(\mathrm{P}^{\text {nth }} \mathrm{O}\right)$ model.

$\mathbf{k}_{\mathbf{i d}} \quad$ Diffusion rate constant $\left(\mathrm{mg} / \mathrm{g} \mathrm{min}^{-0.5}\right)$.

$\mathbf{K}_{\mathbf{F}} \quad$ The Freundlich parameter (mg L/g).

$\mathbf{K}_{\mathbf{L}} \quad$ The constant of equilibrium adsorption (L/mg).

Ks The adsorption affinity constant $(\mathrm{L} / \mathrm{mg})$.

$\mathbf{K}_{\mathbf{R P}} \quad$ Redlich-Peterson model constant $(\mathrm{L} / \mathrm{g})$.

m Adsorbent mass (g) 
Ms System heterogeneity index of the Sips model.

n Sorption reaction order.

$\mathbf{n}_{\mathbf{f}} \quad$ Heterogeneity index of the Freundlich model.

PFO Pseudo first order.

PSO Pseudo second order.

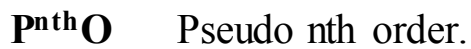

PZJS Treated powder of ziziphus jujuba stones.

T Temperature $\left({ }^{\circ} \mathrm{C}\right.$ or $\left.{ }^{\circ} \mathrm{K}\right)$.

$\mathbf{t} \quad$ Time (min).

V Medium solution volume (L).

Qe The amount adsorbed at equilibrium (mg/g).

$\mathbf{Q}_{\mathbf{m}} \quad$ The constant that expresses the recovery of the complete monolayer $(\mathrm{mg} / \mathrm{g})$.

Q $\quad$ The amount adsorbed at instant $\mathrm{t}(\mathrm{mg} / \mathrm{g})$.

Qads The amount adsorbed at one cycle (mg/g).

Qdes The amount desorbed at one cycle $(\mathrm{mg} / \mathrm{g})$.

a Redlich-Peterson model constant ( $\mathrm{L} \mathrm{mg} / \mathrm{g})$.

$\boldsymbol{\beta}_{\mathbf{t}}$ Mathematical function of "F" function,

$\boldsymbol{\beta}$ Surface heterogeneity index of R-P model. 
$\Delta \mathbf{H}^{\circ} \quad$ The change in enthalpy $(\mathrm{J} / \mathrm{mol})$.

$\Delta \mathbf{G}^{\circ} \quad$ The change in Gibbs free energy $(\mathrm{J} / \mathrm{mol})$.

$\Delta \mathbf{S}^{\circ} \quad$ The change in entropy $(\mathrm{J} / \mathrm{mol} \mathrm{K})$. 


\section{Introduction}

During their manufacturing activities, the petroleum, petrochemical, chemical and pharmaceutical industries produce huge amounts of polluted water, where its toxicity and its carcinogenicity have serious consequences on human health, as well as on the environment even at very low concentrations [1], leading to a systematic ecological disorder. It is therefore necessary to treat these waters before their recycling or rejection in the environment. In this background, and over the last decades, the treatment of these waters has always been a very important area of research and a topical subject for which thousands of research studies have been carried out, and huge budgets have been established in order to discover appropriate solutions to treat industrial water at reasonable costs.

As it is known, industrial water treatment is defined as the process of removing contaminants from industrial water, whether inorganics, such as heavy metals (arsenic, lead, cadmium), nitrates, phosphates, or organics, such as pharmaceutical effluents, detergents, acids, oils, diluents and dyes.

In fact, all industries that use dyes in their processes, such as textiles production, discharge more than $10^{9} \mathrm{~kg}$ tons of dye, including 8000 associated molecules [1], to the natural environment, making their biodegradation impossible, and hence human intervention is necessary. In this context, several classical and modern methods have been used to treat these polluted waters. Among these techniques, adsorption is one of the most widely used in wastewater treatment processes worldwide [2], due to its rapidity, performances and its economic efficiency [3].

Therefore, much research has recently been released on dye removal with a wide range of convenient powdered products already in use, such as activated carbon [4], clays [5], biosorbents [6]... etc. Nevertheless, it is essential to point out some issues related to the use of 
these materials, such as the regeneration problems and the quantities of powder recovered after an adsorption test. Indeed, in the last decade, scientific research has focused on the development of new adsorbent materials aimed at avoiding the disadvantages of these conventional materials. In this aim, encapsulation is proposed in this study to skip these issues on the one hand, and to gain a number of benefits such as high adsorption capacity, high porosity, uniform size and ease of regeneration on the other hand. As a result, several polymers have been considered to perform the encapsulation step, such as for example alginate $[7,8]$, chitosan $[9,10]$, cellulose $[11,12]$, etc. In this study, sodium alginate was chosen with regards to its numerous advantages, such as its simplicity, its biocompatibility and its low cost [13,14] compared to other encapsulating agents.

This study focused therefore on the preparation of a powdered material from Ziziphus jujuba stones and its encapsulation with sodium alginate, considering ratios in the range from 1 to 2 . The efficiency of the prepared materials was evaluated in a batch system by adsorption of methylene blue dye, which was chosen as a model molecule of basic dye. In addition, the characteristics of the prepared beads were also examined by different techniques of characterization, such as Fourier transform infrared spectroscopy (FTIR), scanning electron microscopy (SEM), X-ray fluorescence (XRF), thermogravimetric analysis (TGA), BrunauerEmmett-Teller method (BET) and the point of zero charges (pHPzC). In addition, the reusability of the prepared beads was also assessed. 


\section{Materials and methods}

\subsection{Chemicals}

All products used in this work were purchased from Sigma Aldrich, namely sodium alginate, phosphoric acid, hydrochloric acid, sodium hydroxide, inorganic salt $\mathrm{NaCl}$ and humic acid.

Table 1 summarizes the main characteristics of the model dye, methylene blue (MB).

\subsection{Preparation of the adsorbents}

The preparation protocol used in this paper consisted firstly of preparing an adsorbent material in powder form, which was then encapsulated using sodium alginate. The considered protocol is given thereafter. Ziziphus jujuba stones in the form of a treated powder (PZJS) were obtained according to the following procedure: the stones were crushed, washed, sieved then dried, and finally, $10 \mathrm{~g}$ of this dried powder was mixed with $102 \mathrm{ml}$ of phosphoric acid $(1 \mathrm{M})$. The mixture was kept in agitation at room temperature for 24 hours and then washed several times. When the supernatant $\mathrm{pH}$ became close to the natural $\mathrm{pH}(6.2)$, the product was inserted into a drying oven at $50{ }^{\circ} \mathrm{C}$, then crushed and sieved for another time, and then stored in a desiccator.

Once the PZJS was ready, the beads of Ziziphus jujuba stones (BZJS) were prepared by encapsulation using sodium alginate, which shows the ability of forming hydrogels in the presence of divalent cations [15-17]. To this end, the encapsulation method used in this paper consisted of mixing a mass of PZJS with a sodium alginate solution ( 2 percent) and then keeping them in agitation; where the ratio of PZJS/Alginate varied between 1 and 2 . When the blend PZJS/Alginate became homogeneous, it was added by means of a peristaltic pump into a divalent solution of $\mathrm{CaCl}_{2}$ to allow the formation of beads by a quick reaction between the alginate and the crosslinking agent at the surface; this must be accomplished under agitation to avoid the consumption of $\mathrm{Ca}^{2+}$ cations. The beads obtained were stirred with the $\mathrm{CaCl}_{2}$ solution 
for 12 hours; next, dried at room temperature and then stored under the abbreviations BZJS 1 and BZJS2 respectively for the ratios $1: 1$ and 1:2 to carry out the adsorption tests.

\subsection{Adsorption study}

The amount of dye adsorbed was determined using Eq. 1 (Table 2); all the adsorption and desorption tests were performed in batch mode. Several parameters that can impact the adsorption of methylene blue on the adsorbents were evaluated, such as temperature, initial $\mathrm{pH}$, initial concentration, ionic strength and the impact of the presence of organic compounds.

\subsection{Kinetics of adsorption}

MB adsorption kinetics on BZJS were examined in a batch system at room temperature $\left(25^{\circ} \mathrm{C}\right)$. The objective was to examine the variation of the adsorbed quantity as a function of two parameters, the time and the initial dye concentration. In this context, three methylene blue solutions were prepared with different initial concentrations ranging from 50 to $200 \mathrm{mg} / \mathrm{L}$.

In a $200 \mathrm{ml}$ beaker, a mass of $100 \mathrm{mg}$ of adsorbent was introduced in $100 \mathrm{ml}$ of MB solution at a stirring speed of $250 \mathrm{rpm}$. After a well-defined time interval, samples were taken to be analyzed using a Shimadzu Spectrophotometer UV-1700.

Kinetics modeling has a major impact on the design of the adsorption system [18]. In order to elucidate the adsorption mechanism, five models were considered: the pseudo-first-order (Eq. 2), the pseudo-second-order (Eq. 3) and the pseudo-nth-order (Eq. 4) models, as well as the Boyd (Eq. 5) and Weber-Morris models (Eq. 6).

The first model used in this part to describe the adsorption kinetics of MB onto BZJS was the pseudo-first-order (PFO) model, also known as the mass transfer model [19] (Eq. 2 in table 2). Among the models applied, the pseudo-second-order (PSO) model (Eq. 3) which is based on chemisorption $[18,19]$. The Pseudo-nth-order $\left(\mathrm{P}^{\text {nth }} \mathrm{O}-\right.$ Eq. 4$)$ is one of the commonly used 
models in the literature; it is used to avoid fixing the value of $n$ as in the previous models $(n=1$ for PFO and $n=2$ for PSO) [20], to be closer to experimental results.

Otherwise, the Boyd and Weber-Morris models were considered to better understand the diffusion mechanism as well as the limiting step that controls the adsorption process [21,22]. The Boyd model (Eq. 5) was applied to discriminate between two mechanisms and to determine what step controls the adsorption process, between the diffusion into the pores and the diffusion film $[18,23,24]$. In this model, the formula of $\beta_{t}$ is given according to the fraction value $(F=$ $\mathrm{Qe} / \mathrm{Qt})$

The Weber-Morris model (Eq. 6) is commonly used in the literature and refers to as the intraparticle diffusion model [25], showing the variation of the adsorbed quantity in relation to $\mathrm{t}^{1 / 2}$.

\subsection{Isotherm study}

The adsorption isotherm tests were performed by contacting the MB solutions at different concentrations (between 50 and $1200 \mathrm{mg} / \mathrm{L}$ ) with adsorbent masses added to have a ratio of $\mathrm{m} / \mathrm{v}$ equal to 1 . These mixtures were kept under constant stirring equal to $250 \mathrm{rpm}$ for $48 \mathrm{~h}$ with a well-controlled temperature $\left(25,30\right.$ and $\left.40{ }^{\circ} \mathrm{C}\right)$. Once the equilibrium was reached the solutions were separated, then analyzed and the adsorbed quantities were calculated using Eq. 1.

Classical isotherms modeling were considered to correlate the experimental data, namely the classical Langmuir, Freundlich, Sips, and Redlich-Peterson models.

The empirical Langmuir model relies on the following hypotheses: monolayer adsorption, the adsorbent surface is homogeneous and the lateral interactions between the adsorbed molecules can be neglected. This empirical Langmuir model [22] is defined by Eq. 7 (Table 2). 
Unlike the Langmuir model, the Freundlich model (Eq. 8 - Table 2) assumes an adsorption on a heterogeneous surface at sites with different adsorption energies and multilayer adsorption possibility [10].

The sips and Redlich-Peterson models are a combination of the two above models, Freundlich and Langmuir models. The model of Redlich-Peterson (Eq. 9 [26]) supposes an adsorption with constant enthalpies and also constant adsorption energies as a homogeneous monolayer [26]. The Sips model (Eq. 10 [27]) depends on the values of its parameters. When the $\beta$ parameter tends towards 1, the Sips equation becomes the Langmuir equation, and for low concentrations, the sips model becomes close to the Freundlich model.

\subsection{Initial pH effect}

The adsorption of the organic dyes is often strongly influenced by the solution's $\mathrm{pH}$, and the examination of its impact can be very helpful to understand the adsorption mechanism. In this study, the $\mathrm{pH}$ effect was investigated by contacting a volume of $50 \mathrm{ml}$ of $\mathrm{MB}$ in beakers of 100 $\mathrm{ml}$ where the initial concentration was $100 \mathrm{mg} / \mathrm{L}$ and containing $50 \mathrm{mg}$ of adsorbent at room temperature, at $25^{\circ} \mathrm{C}$ and a constant stirring speed of $250 \mathrm{rpm}$. The initial $\mathrm{pH}$ range varied from 2 to 12 , which was adjusted using sodium hydroxide or hydrochloric acid. The obtained suspensions were analyzed by visible UV after 48 hours of stirring.

\subsection{Effect of $\mathrm{NaCl}$ and Humic Acid}

The impact of ionic strength on the MB adsorption onto BZJS was examined using $\mathrm{NaCl}$; this inorganic salt was used at a steady concentration of $0.1 \mathrm{~mol} / \mathrm{L}$, with initial concentrations of $\mathrm{MB}$ ranging from 50 to $1000 \mathrm{mg} / \mathrm{L}$. The operating procedure consisted of adding the $\mathrm{NaCl}$ to a $50 \mathrm{ml} \mathrm{MB}$ solution, which was then put in contact with the adsorbent material; after constant stirring for 48 hours the suspension was separated and analyzed. Otherwise, humic acid was also used as an influencing agent to study the impact of organic compounds; the protocol used was the same that used for the impact of the ionic strength. 


\subsection{Effect of Temperature and Thermodynamic Parameters}

The effect of the temperature was carried out in the range of 10 to $40^{\circ} \mathrm{C}$ and the experiments were carried out similarly to adsorption isotherms. Therefore, considering Eqs. 11 and 12 the feasibility of the MB adsorption process onto BZJS was checked [28].

\subsection{Regeneration study of BZJS1 and BZJS2}

Achieving an efficient regeneration is among the objectives of the encapsulation, to minimize treatment costs in view of subsequent industrial application [3]. For this purpose, $100 \mathrm{mg}$ of beads was introduced in a MB solution at $100 \mathrm{mg} / \mathrm{L}$ initial concentration and at natural $\mathrm{pH}(6.2)$. The mixture was kept under agitation for $48 \mathrm{~h}$; once equilibrium was reached, the used beads were separated, cleaned several times with distilled water, and then dried at atmospheric temperature. These dried beads were introduced again into a distilled water solution adjusted to the minimum $\mathrm{pH}$ of adsorption by adding droplets of $\mathrm{HCl}$; the suspension was stirred for 48 hours. This cycle was repeated six times and the regeneration efficiency was calculated using Eq. 13.

\subsection{Materials characterization}

An Agilent Technologies Fourier Transform Spectrophotometer (FTIR) (cary 600 series FTIR spectrometer) was used to examine the surface chemistry of BZJS1 and BZJS2 where the infrared spectra ranged from $4000 \mathrm{~cm}$ to $550 \mathrm{~cm}^{-1}$.

The micromorphology of PZJS, BZJS1 and BZJS2 was examined by scanning electron spectroscopy where the captures were made by a Hitachi S-3000N SEM. In addition, using the same apparatus elemental analysis was examined with energy dispersive X-ray diffraction (EDX), as well as X-ray fluorescence (XRF) using a ZSX Primus IV-Rigaku device. 
The nitrogen adsorption and desorption isotherms were considered to examine the porous structure. Before starting the characterization, a vacuum degassing at a temperature of $130{ }^{\circ} \mathrm{C}$ must be carried out on the sample; next, specific surface, size, and pore volume were calculated.

Moreover, thermogravimetric analysis (TGA) of the prepared materials was carried out using SDT Q600 V20.9 Build 20 thermal gravimetric, at temperatures ranging from 40 to $900{ }^{\circ} \mathrm{C}$ with a heating flow of $10{ }^{\circ} \mathrm{C} /$ minute.

The zero charge point (pHpzc) for each material corresponds to a zero charge potential on the adsorbent surface; it is very helpful for understanding the interaction mechanism between the liquid and solid phases. A simple protocol was followed which consisted of using a series of 11 beakers of $50 \mathrm{ml}$ containing a suspension of $50 \mathrm{mg}$ of adsorbent with $50 \mathrm{ml}$ of distilled water where the initial pHs of water were adjusted from 2 to 12 using $\mathrm{HCl}$ or $\mathrm{NaOH}$. These suspensions were kept under stirring for $48 \mathrm{~h}$ and then the final $\mathrm{pH}$ of each beaker was measured. Finally, the results obtained are displayed on a graph according to the following expression $\Delta \mathrm{pH}=\mathrm{f}(\mathrm{pHi})$

\section{Results and discussion}

\subsection{Characterization of the materials}

In order to quantify the different functional groups present on the surface of the prepared materials and after MB adsorption, an FTIR analysis was carried out; the results obtained are shown in Fig. 1. A broad band was observed at about $3425 \mathrm{~cm}^{-1}$, which can be attributed to vibrations of $\mathrm{OH}, \mathrm{NH}$ and $\mathrm{COOH}$ present on the surface of materials, in agreement with the related literature [29]. The vibrations of $\mathrm{CH}_{2}$ and $\mathrm{CH}_{3}$ were represented by small bands at 2853 and $2923 \mathrm{~cm}^{-1}$ respectively. The peak at $1624 \mathrm{~cm}^{-1}$ can be assigned to asymmetric and symmetric elongations of $\mathrm{C}=\mathrm{O}$ in carboxylic groups, and peak at approximately $1262 \mathrm{~cm}^{-1}$ can be demonstrated by stretching vibrations of $\mathrm{C}-\mathrm{O}$. Moreover, Fig. 1 demonstrates the presence 
of $\mathrm{C}-\mathrm{N}$ amines, $\mathrm{C}-\mathrm{H}$ in aromatic rings and some phosphorus compounds owing to the existence of certain peaks between 1267 and $700 \mathrm{~cm}^{-1}$ [30]. The BZJS curves show small bands at 1055 and $1031 \mathrm{~cm}^{-1}$, which can be attributed to the $\mathrm{C}-\mathrm{O}, \mathrm{C}-\mathrm{O}-\mathrm{H}$ and $\mathrm{C}-\mathrm{C}$ vibration modes on alginate carbohydrate rings [31]. These findings indicate that BZJS1 and BZJS2 have similar functional groups with some variations in the intensity of some peaks, owing to the different ratios between Ziziphus jujuba powder and sodium alginate during the preparation step.

These results also show that after encapsulation, some peaks are shifted or reduced in intensity and others have disappeared, which indicates that the encapsulation was efficiently done; the same remark after $\mathrm{MB}$ adsorption confirming that $\mathrm{MB}$ adsorption onto BZJS was efficiently achieved.

PZJS, BZJS1, and BZJS2 micromorphologies are displayed in Fig. 2 (a, b, c), showing a heterogeneous surface before encapsulation for the treated Ziziphus jujuba stones in powder form [32,33]. According to Fig. 2 (b and c), BZJS1 and BZJS2 had a spherical structure, with a more radiated (rigorous) structure for BZJS1 compared to BZJS2; this finding may be due to a higher alginate ratio for BZJS1, which promotes the proper integration of PZJS into the alginate matrix.

With the aim to realize a quantitative comparison between PZJS, BZJS1, and BZJS2, an elementary analysis using XRF and EDX characterizations were performed and the obtained results are collected in Fig. 3 and Table 3. Both techniques show that the elemental composition was changed after the encapsulation of PZJS; this change can be seen in the decrease of certain elements percentages, such as carbon, as well as the increase in the percentage of some other elements, such as oxygen, and the appearance of calcium which can characterize the efficiency of encapsulation. Furthermore, the XRF results show that the percentage of Ca for BZJS1 was 
higher than that for BZJS2; this finding must be related to the considered ratio in the bead preparation step.

The porous structure of an adsorbent material is characterized by the measurement of its specific surface and its pore volume. In this context, the textural properties of BZJS1 (Best adsorbent) were examined, and hence the $77 \mathrm{~K}$ nitrogen adsorption-desorption isotherm onto BZJS1 is shown in Fig. 4 and the corresponding parameters are reported in Table 4. As observed, the BZJS1 had a specific area of $15.685 \mathrm{~m}^{2} / \mathrm{g}$, a pore volume of $0.032 \mathrm{~cm}^{3} / \mathrm{g}$ and a pore diameter of $4.11 \mathrm{~nm}$, showing its low porosity; this can be due to the effect of alginate that hinders or damages the creation of porosity [34].

Thermogravimetric analysis was carried out for PZJS, BZJS1, and BZJS2 at temperatures ranging from 40 to $900{ }^{\circ} \mathrm{C}$. The obtained data are shown in Fig. 5. The three samples show curves characterized by 3 stages. The first stage (from $40{ }^{\circ} \mathrm{C}$ to $230{ }^{\circ} \mathrm{C}$ for PZJS and from 30 ${ }^{\circ} \mathrm{C}$ to $200{ }^{\circ} \mathrm{C}$ for BZJS) defined by a weight loss of approximately $12 \%$ which can be attributed to the remove of the adsorbed water and the volatile matter attached to the surface [35]; the second stage (from $230{ }^{\circ} \mathrm{C}$ to $380^{\circ} \mathrm{C}$ for PZJS and from $200{ }^{\circ} \mathrm{C}$ to $380{ }^{\circ} \mathrm{C}$ for BZJS) was due to the decomposition of the cellulosic elements [33]; and the last stage (from $380{ }^{\circ} \mathrm{C}$ to the end of the analysis) corresponded to decomposition reactions of organic carbon and inorganic oxygen as well as by further degradation of the alginate [36,37]. This final phase can also be defined by the breaking of the $\mathrm{C}-\mathrm{H}$ and $\mathrm{C}-\mathrm{O}$ bands [38]. At the end of the analysis, we notice that there is a weight loss of $88.74,76.07$ and 74.78 for PZJS, BZJS1, and BZJS2 respectively, which indicates that the encapsulation may slightly increase the thermal stability.

Fig. 6 shows that the isoelectric points obtained were 3.84, 7.41 and 7.22 for PZJS, BZJS1, and BZJS2, respectively, indicating that the encapsulation makes the surface character of the materials more alkaline. This finding shows that when the $\mathrm{pH}$ of the solution is below the 
isoelectric point value (7.41 for BZJS1 and 7.22 for BZJS2), the BZJS surface functional groups are protonated by an excess of $\mathrm{H}^{+}$protons, and in the opposite case (solution $\mathrm{pH}$ is greater the isoelectric point value) the BZJS surface functional groups are deprotonated by the excess of $\mathrm{OH}^{-}$ions.

\subsection{Effect of encapsulation on the MB adsorption capacity}

In an attempt to investigate the impact of the encapsulation process on the MB adsorption efficiency, the maximum adsorbed quantity of MB onto the PZJS, BZJS1 and BZJS2 obtained from the $25^{\circ} \mathrm{C}$ adsorption isotherms are shown in Fig. 7. As observed, the encapsulation strongly and positively affected the performances, since the adsorbed quantity increased from 160.85 (PZJS) to $737.13 \mathrm{mg} / \mathrm{g}$ (BZJS1) and $660.12 \mathrm{mg} / \mathrm{g}$ (BZJS2) respectively.

\subsection{MB adsorption isotherms Study}

Adsorption isotherms are usually considered to establish an adsorbent-adsorbate relationship, and to give insight with regards to the adsorption mode in order to achieve a pilot design [39].

The results obtained from the adsorption isotherms of MB onto BZJS1 and BZJS2 at different temperatures $\left(10,25,30\right.$ and $\left.40{ }^{\circ} \mathrm{C}\right)$ are illustrated in Fig. 8, showing isotherms of type $\mathrm{L}$ according to the GILL classification; such form of isotherm is characterized by a strong affinity between the adsorbent-adsorbate duo with a monolayer adsorption mode [40]. Moreover, the adsorbed quantities decreased from 767.10 to $627.55 \mathrm{mg} / \mathrm{g}$ for the BZJS1, and from 680.10 to 493.26 for the BZJS2 for temperatures increasing from 10 to $40{ }^{\circ} \mathrm{C}$; these high values show the efficiency of the prepared materials for the adsorption of cationic organic pollutants.

Otherwise, the results of the modeling of experimental data for MB adsorption isotherms onto BZJS1 and BZJS2 are shown in Fig. 8, and the corresponding data are collected in Table 5. The selection of the best model is generally based on the high value of the $\mathrm{R}^{2}$ correlation factor, as 
well as the small delta between the experimentally adsorbed quantity values and that found theoretically by the considered model [41].

From Table 5, Langmuir, Sips and Redlich Peterson's models showed high correlation coefficients for the four temperatures tested $\left(10,25,30\right.$, and $\left.40{ }^{\circ} \mathrm{C}\right)$; however, the Sips and Langmuir models demonstrated theoretical adsorbed amounts a little far from that found experimentally. To conclude this part, it can be assumed that the Redlich Peterson model is the most appropriate to describe the MB adsorption process onto BZJS1 and BZJS. The Redlich Peterson model can describe both mono and multilayer adsorption. However, whatever the temperature, the $\beta$ coefficient of this latter model was very close to 1 , showing that the Redlich Peterson model approached the Langmuir model, indicating a monolayer mode for the MB adsorption onto both materials.

\subsection{MB adsorption kinetics}

\subsubsection{Effect of the contact time and the MB initial concentration}

As observed (Fig. 9), for both materials, especially in the case of high initial concentrations, the equilibrium time was slowly achieved. Fig. 9 also shows that the adsorbed quantity increased with the initial concentration, from 45.80 to $182.59 \mathrm{mg} / \mathrm{L}$ for BZJS1 and from 45.86 to 177.88 $\mathrm{mg} / \mathrm{L}$ for BZSJ2 for initial concentrations increasing from 50 to $200 \mathrm{mg} / \mathrm{L}$. It is due to the driving force that increases with the initial concentration. It can also be seen that the adsorption of $\mathrm{MB}$ onto both materials was characterized by three stages, fast adsorption in the first stage compared to the two others. It is due to the availability of free adsorption sites at the beginning of the experiment and occurring on the external surface of BZJS1 and BZJS2, facilitating the adsorption of MB. The second stage of slower adsorption appears when the free sites are occupied, making MB adsorption more difficult. The third stage is defined by a saturation of 
the available adsorption sites, which makes the MB adsorption close to impossible; this stage is illustrated graphically by the equilibrium phase.

\subsubsection{Kinetics modeling}

Results of MB adsorption kinetics modeling onto BZJS1 and BZJS2 are shown in Fig. 9 and Table 6. Regardless of the initial concentration, both materials showed excellent correlation factors for all three models (Table 6). Moreover, when comparing the adsorbed experimental quantities with those found theoretically by each model, it was obvious that the PFO model was the most appropriate to describe MB's adsorption kinetics onto BZJS1 and BZJS2 compared to the two other $\left(\mathrm{PSO}, \mathrm{P}^{\text {nth }} \mathrm{O}\right)$ models.

The curves of intra-particle modeling are shown in Fig. 10. Whatever the initial concentration multi-line curves were observed for both materials, meaning that MB adsorption onto BZJS1 and BZJS2 occurred in three stages. These stages can be defined as follows: the first step is the fastest one due to the diffusion of $\mathrm{MB}$ molecules from the boundary layer to the external surface of the adsorbent. The adsorption rate decreases and the MB molecules of external surface are transported to the internal layer of the BZJS in the second step; and the third phase starts when the equilibrium is reached [21].

The data obtained by the Boyd model are shown in Fig. 11. A linear curve which passes through the zero suggest that the diffusion into the pores is the limiting step which controls the adsorption process; while a non-linear curve $\beta=\mathrm{f}(\mathrm{t})$ means that the film diffusion is the limiting step that controls the process $[21,24]$, as it is the case in this study where the curves were not linear for BZJS1 and BZJS2.

\subsection{Initial pH effect}


It is evident from Fig. 12 that the $\mathrm{pH}$ had a significant impact on dye adsorption. It can be noted the efficient adsorption for $\mathrm{pH}$ in the range 6 to 12 , while efficiency decreased at acidic $\mathrm{pH}$. This can be explained by considering the pHpzc values (7.4 for BZJS1 and 7.3 for BZJS2), which can be related to the cations and anions distribution on the adsorbent surface. When the $\mathrm{pH}$ varies towards alkaline values, the $\mathrm{OH}^{-}$anions become more available that facilitates the MB adsorption by electrostatic interactions; while the opposite occurs when the $\mathrm{pH}$ varies towards acidic pH. Fig. 12 also shows that even if the adsorbents were positively charged in the $\mathrm{pH}$ range between 4 and 6 there was a significant adsorbed quantity; this indicates that electrostatic interactions are not the only mode of adsorption involved in the MB adsorption onto BZJS1 and BZJS2, where the adsorption can be achieved by the contribution of sulfur, nitrogen and oxygen electrons or by the $\pi-\pi$ interactions between the aromatic cycles of MB and those of BZJS; this interpretation has recently been assumed by our research group [33].

\subsection{Ionic strength and humic acid effects}

Fig. 13 shows the effect of the ionic strength and the presence of organic compounds onto BZJS1 and BZJS22 adsorption of MB. Regarding the ionic strength, the amount adsorbed strongly decreased for both materials, from 737.17 to $268.95 \mathrm{mg} / \mathrm{g}$ for BZJS1 and from 660.51 to $261.82 \mathrm{mg} / \mathrm{g}$ for BZJS2, indicating a negative impact of $\mathrm{NaCl}$ on the adsorption process, most likely due to the decomposition of the inorganic salt into $\mathrm{Na}^{+}$and $\mathrm{Cl}^{-}$creating competitiveness between $\mathrm{MB}$ molecules and $\mathrm{Na}^{+}$cations for adsorption onto the adsorbents. $\mathrm{A}$ similar impact was observed in the case of humic acid, since the adsorbed quantities decreased to 375.22 and $297.48 \mathrm{mg} / \mathrm{g}$ for BZJS1 and BZJS2, respectively.

\subsection{Regeneration study of BZJS1 and BZJS2}

In view of a future implementation at industrial scale, a regeneration study of the prepared beads was performed (Fig. 14), showing a higher reusability for BZJS1 if compared to BZJS2. Indeed, 
its adsorption performances decreased only slightly, from $99.08 \%$ for the first cycle to $92.01 \%$ for the sixth cycle.

\subsection{Temperature effect on MB adsorption onto BZJS1 and BZJS2}

Fig. 8 shows that the temperature had a negative impact on the adsorption of $\mathrm{MB}$ onto each material, indicating that the adsorption process was exothermic. Furthermore, with the help of the $\mathrm{Qe} / \mathrm{Ce}$ plot as a function of the reverse of the temperature and after the necessary calculations carried out according to Van't Hoff and Gibbs free energy equations, the thermodynamic parameters were determined and reported in Table 7. As shown, the free Gibbs energy was negative proving that the $\mathrm{MB}$ adsorption onto the prepared beads was spontaneous. Negative enthalpies suggest that the adsorption process was exothermic. In addition, on the basis of enthalpies parameters, it can be deduced that $\mathrm{MB}$ adsorption onto both materials was achieved in physisorption mode because the values were within the range of 0 to $-20 \mathrm{~kJ} / \mathrm{mol}$ [5]. Table 7 also shows the positive entropy values which indicate that the BM molecules have a random character at the liquid-solid interface during their adsorption onto BZJS1 and BZJS2 [42].

\subsection{MB adsorption onto various adsorbents}

In this part, a comparison of the performances of the prepared beads (BZJS1 and BZJS2) to those also considered in the available literature for the removal of methylene blue is displayed

in Table 8, which summarizes the maximum adsorbent capacity of each material as well as the number of regeneration cycles with a variety of precursors and encapsulating agents. As observed, BZJS1 displays interesting performances and hence its relevance must be subsequently confirmed at larger scale. 


\section{Conclusion}

In this paper, encapsulation by sodium alginate was used as a proposed solution to avoid some problems encountered with conventional materials in powder form such as the diffic ulty of regeneration. For this purpose, Ziziphus jujuba stones were used as a precursor. The performances of the prepared materials (BZJS1 and BZJS2) were examined in a batch system by adsorption of a cationic dye, methylene blue (MB). The results obtained confirmed that the encapsulation was efficiently carried out, since the adsorption potential of the prepared beads strongly increased from $160.85 \mathrm{mg} / \mathrm{g}$ for PZJS to 767.102 and $680.098 \mathrm{mg} / \mathrm{g}$ for BZJS1 and BZJS2 respectively at $25^{\circ} \mathrm{C}$. Furthermore, the modeling of MB adsorption isotherms showed that whatever the temperature, the Redlich Peterson model led to the most accurate fitting of experimental data. Regarding the adsorption kinetics, the nonlinear models of pseudo-firstorder (PFO), pseudo-second-order (PSO) and pseudo nth order $\left(\mathrm{P}^{\text {nth }} \mathrm{O}\right)$ were considered and the PFO model was found to be the most suitable model to describe the kinetic results. In addition, the Intra particle diffusion model showed that MB adsorption was performed in three steps, and the Boyd model suggested that film diffusion is the limiting step that controls the MB adsorption process onto both materials. Otherwise, the effects of ionic strength and organic compounds have shown that $\mathrm{NaCl}$ and humic acid had a negative impact on the adsorption of MB on both materials. The temperature effect and thermodynamic parameters showed that adsorption of MB onto BZJS1 and BZJS1 was spontaneous and exothermic. The regeneration study concluded on the reusability of the beads, since the MB removal yields were 92.01 and $82.88 \%$ for BZJS1 and BZJS2 even at the sixth cycle. 


\section{Acknowledgments}

The authors gratefully acknowledge the support of the Directorate General for Scientific Research and Technological Development (DGRSDT) of Algeria. 


\section{References}

[1] A.B. Albadarin, S. Solomon, T.A. Kurniawan, C. Mangwandi, G. Walker, Single, simultaneous and consecutive biosorption of $\mathrm{Cr}(\mathrm{VI})$ and Orange II onto chemically modified masau stones, Journal of Environmental Management. 204 (2017) 365-374. https://doi.org/10.1016/j.jenvman.2017.08.042.

[2] L. Zhao, J.P. Basly, M. Baudu, Macroporous alginate/ferrihydrite hybrid beads used to remove anionic dye in batch and fixed-bed reactors, Journal of the Taiwan Institute of Chemical Engineers. 74 (2017) 129-135. https://doi.org/10.1016/j.jtice.2017.02.006.

[3] F. Ogata, T. Nakamura, N. Kawasaki, Adsorption capability of virgin and calcined wheat bran for molybdenum present in aqueous solution and elucidating the adsorption mechanism by adsorption isotherms, kinetics, and regeneration, Journal of Environme ntal Chemical Engineering. 6 (2018) 4459-4466. https://doi.org/10.1016/j.jece.2018.06.047.

[4] Z. Noorimotlagh, S.A. Mirzaee, S.S. Martinez, S. Alavi, M. Ahmadi, N. Jaafarzadeh, Adsorption of textile dye in activated carbons prepared from DVD and CD wastes modified with multi-wall carbon nanotubes: Equilibrium isotherms, kinetics and thermodynamic study, Chemical Engineering Research and Design. 141 (2019) 290-301. https://doi.org/10.1016/j.cherd.2018.11.007.

[5] I. Chaari, E. Fakhfakh, M. Medhioub, F. Jamoussi, Comparative study on adsorption of cationic and anionic dyes by smectite rich natural clays, Journal of Molecular Structure. 1179 (2019) 672-677. https//doi.org/10.1016/j.molstruc.2018.11.039.

[6] C.E. de F. Silva, B.M.V. da Gama, A.H. da S. Gonçalves, J.A. Medeiros, A.K. de S. Abud, Basic-dye adsorption in albedo residue: Effect of $\mathrm{pH}$, contact time, temperature, dye concentration, biomass dosage, rotation and ionic strength, Journal of King Saud University - Engineering Sciences. (2019) S1018363918304501. https://doi.org/10.1016/j.jksues.2019.04.006. 
[7] M.A. Dominguez, M. Etcheverry, G.P. Zanini, Evaluation of the adsorption kinetics of brilliant green dye onto a montmorillonite/alginate composite beads by the shrinking core model, Adsorption. 25 (2019) 1387-1396. https://oi.org/10.1007/s10450-019-00101-w.

[8] S. Biswas, T.K. Sen, A.M. Yeneneh, B.C. Meikap, Synthesis and characterization of a novel Ca-alginate-biochar composite as efficient zinc $\left(\mathrm{Zn}^{2+}\right)$ adsorbent: Thermodynamics, process design, mass transfer and isotherm modeling, Separation $\begin{array}{lllll}\text { Science } & \text { and } & \text { Technology. } & 54 & \text { (2019) }\end{array}$ https://doi.org/10.1080/01496395.2018.1527353.

[9] S. Dandil, D. Akin Sahbaz, C. Acikgoz, Adsorption of $\mathrm{Cu}(\mathrm{II})$ ions onto crosslinked chitosan/Waste Active Sludge Char (WASC) beads: Kinetic, equilibrium, and thermodynamic study, International Journal of Biological Macromolecules. 136 (2019) 668-675. https://doi.org/10.1016/j.ijbiomac.2019.06.063.

[10] T.T.N. Le, V.T. Le, M.U. Dao, Q.V. Nguyen, T.T. Vu, M.H. Nguyen, D.L. Tran, H.S. Le, Preparation of magnetic graphene oxide/chitosan composite beads for effective removal of heavy metals and dyes from aqueous solutions, Chemical Engineering $\begin{array}{lll}\text { Communications. } & 206 & \text { (2019) }\end{array}$ https://doi.org/10.1080/00986445.2018.1558215.

[11] Y. Pan, H. Xie, H. Liu, P. Cai, H. Xiao, Novel cellulose/montmorillonite mesoporous composite beads for dye removal in single and binary systems, Bioresource Technology. 286 (2019) 121366. https://doi.org/10.1016/j.biortech.2019.121366.

[12] H. Xie, Y. Pan, H. Xiao, H. Liu, Preparation and characterization of amphoteric cellulosemontmorillonite composite beads with a controllable porous structure, J Appl Polym Sci. 136 (2019) 47941. https://oi.org/10.1002/app.47941. 
[13] J. Kurczewska, M. Cegłowski, G. Schroeder, Alginate/PAMAM dendrimer - Halloys ite beads for removal of cationic and anionic dyes, International Journal of Biological Macromolecules. 123 (2019) 398-408. https://doi.org/10.1016/j.ijbiomac.2018.11.119.

[14] N. Fiol, J. Poch, I. Villaescusa, Grape Stalks Wastes Encapsulated in Calcium Alginate Beads for Cr(VI) Removal from Aqueous Solutions, Separation Science and Technology. 40 (2005) 1013-1028. https//doi.org/10.1081/SS-200048041.

[15] R. Torres-Caban, C.A. Vega-Olivencia, L. Alamo-Nole, D. Morales-Irizarry, F. RomanVelazquez, N. Mina-Camilde, Removal of Copper from Water by Adsorption with Calcium-Alginate/Spent-Coffee-Grounds Composite Beads, Materials. 12 (2019) 395. https://doi.org/10.3390/ma12030395.

[16] B. Wang, Y. Wan, Y. Zheng, X. Lee, T. Liu, Z. Yu, J. Huang, Y.S. Ok, J. Chen, B. Gao, Alginate-based composites for environmental applications: a critical review, Critical Reviews in Environmental Science and Technology. 49 (2019) 318-356. https://oi.org/10.1080/10643389.2018.1547621.

[17] B. Wang, B. Gao, Y. Wan, Comparative study of calcium alginate, ball-milled biochar, and their composites on aqueous methylene blue adsorption, Environ Sci Pollut Res. 26 (2019) 11535-11541. https://doi.org/10.1007/s11356-018-1497-1.

[18] Y.H. Magdy, H. Altaher, Kinetic analysis of the adsorption of dyes from high strength wastewater on cement kiln dust, Journal of Environmental Chemical Engineering. 6 (2018) 834-841. https://doi.org/10.1016/j.jece.2018.01.009.

[19] M.C. Stanciu, M. Nichifor, Influence of dextran hydrogel characteristics on adsorption capacity for anionic dyes, Carbohydrate Polymers. $199 \quad$ (2018) 75-83. https://oi.org/10.1016/j.carbpo1.2018.07.011.

[20] T.S. Pessôa, L.E. de Lima Ferreira, M.P. da Silva, L.M. Pereira Neto, B.F. do Nascimento, T.J.M. Fraga, E.F. Jaguaribe, J.V. Cavalcanti, M.A. da Motta Sobrinho, Açaí waste 
beneficing by gasification process and its employment in the treatment of synthetic and raw textile wastewater, Journal of Cleaner Production. 240 (2019) 118047. https://oi.org/10.1016/j.jclepro.2019.118047.

[21] S. Li, Z. Zeng, W. Xue, Adsorption of lead ion from aqueous solution by modified walnut shell: kinetics and thermodynamics, Environmental Technology. 40 (2019) 1810-1820. https://doi.org/10.1080/09593330.2018.1430172.

[22] G. Polat, Y.S. Açikel, Synthesis and Characterization of Magnetic Halloysite-Alginate Beads for the Removal of Lead(II) Ions from Aqueous Solutions, J Polym Environ. 27 (2019) 1971-1987. https://doi.org/10.1007/s10924-019-01489-w.

[23] B. Choudhary, D. Paul, Isotherms, kinetics and thermodynamics of hexavalent chromium removal using biochar, Journal of Environmental Chemical Engineering. 6 (2018) 23352343. https://doi.org/10.1016/j.jece.2018.03.028.

[24] S.U. Din, T. Mahmood, A. Naeem, M. Hamayun, N.S. Shah, Detailed kinetics study of arsenate adsorption by a sequentially precipitated binary oxide of iron and silicon, $\begin{array}{lllll}\text { Environmental } & \text { Technology. } & 40 \quad \text { 261-269. }\end{array}$ https://doi.org/10.1080/09593330.2017.1385649.

[25] W.J. Weber, J.C. Morris, Kinetics of Adsorption on Carbon from Solution, Journal of the $\begin{array}{lllll}\text { Sanitary } & \text { Engineering } & \text { Division. } & 89 & \text { (1963) }\end{array}$ https://cedb.asce.org/CEDBsearch/record.jsp?dockey=0013042 (accessed December 2, 2018).

[26] N. Maaloul, P. Oulego, M. Rendueles, A. Ghorbal, M. Díaz, Synthesis and characterization of eco-friendly cellulose beads for copper (II) removal from aqueous solutions, Environ Sci Pollut Res. (2019). https^/doi.org/10.1007/s11356-018-3812-2.

[27] F. Ahmadpoor, S.A. Shojaosadati, S.Z. Mousavi, Magnetic silica coated iron carbide/alginate beads: Synthesis and application for adsorption of $\mathrm{Cu}$ (II) from aqueous 
solutions, International Journal of Biological Macromolecules. 128 (2019) 941-947. https://doi.org/10.1016/j.ijbiomac.2019.01.173.

[28] T. Benhalima, H. Ferfera-Harrar, Eco-friendly porous carboxymethyl cellulose/dextran sulfate composite beads as reusable and efficient adsorbents of cationic dye methylene blue, International Journal of Biological Macromolecules. 132 (2019) 126-141. https://doi.org/10.1016/j.ijbiomac.2019.03.164.

[29] $\mathrm{P}$. Tiwari, Adsorption of $\mathrm{Pb}$ (II), $\mathrm{Cu}$ (II), and $\mathrm{Zn}$ (II) Ions onto Urtica dioica Leaves (UDL) as a Low Cost Adsorbent: Equilibrium and Thermodynamic Studies, MC. 5 (2017) 11. https://doi.org/10.11648/j.mc.20170501.13.

[30] M.A. Nahil, P.T. Williams, Pore characteristics of activated carbons from the phosphoric acid chemical activation of cotton stalks, Biomass and Bioenergy. 37 (2012) 142-149. https:/doi.org/10.1016/j.biombioe.2011.12.019.

[31] M.A. Khan, S.M. Wabaidur, M.R. Siddiqui, A.A. Alqadami, A.H. Khan, Silicomanganese fumes waste encapsulated cryogenic alginate beads for aqueous environment de-colorization, Journal of Cleaner Production. $244 \quad$ (2020) 118867. https://doi.org/10.1016/j.jclepro.2019.118867.

[32] S. Marković, A. Stanković, Z. Lopičić, S. Lazarević, M. Stojanović, D. Uskoković, Application of raw peach shell particles for removal of methylene blue, Journal of $\begin{array}{lllll}\text { Environmental } & \text { Chemical } & \text { Engineering. } & 3 & \text { (2015) }\end{array}$ https://oi.org/10.1016/j.jece.2015.04.002.

[33] A. Guediri, A. Bouguettoucha, D. Chebli, N. Chafai, A. Amrane, Molecular dynamic simulation and DFT computational studies on the adsorption performances of methylene blue in aqueous solutions by orange peel-modified phosphoric acid, Journal of Molecular Structure. (2019) 127290. https://doi.org/10.1016/j.mols truc.2019.127290. 
[34] A. Oussalah, A. Boukerroui, A. Aichour, B. Djellouli, Cationic and anionic dyes removal by low-cost hybrid alginate/natural bentonite composite beads: Adsorption and reusability studies, International Journal of Biological Macromolecules. 124 (2019) 854-862. https:/doi.org/10.1016/j.ijbiomac.2018.11.197.

[35] A. Nasrullah, B. Saad, A.H. Bhat, A.S. Khan, M. Danish, M.H. Isa, A. Naeem, Mangosteen peel waste as a sustainable precursor for high surface area mesoporous activated carbon: Characterization and application for methylene blue removal, Journal of $\begin{array}{llll}\text { Cleaner } & \text { Production. } & 211 & \text { (2019) }\end{array}$ https://oi.org/10.1016/j.jclepro.2018.11.094.

[36] N. Belhouchat, H. Zaghouane-Boudiaf, C. Viseras, Removal of anionic and cationic dyes from aqueous solution with activated organo-bentonite/sodium alginate encapsulated beads, Applied Clay $\quad$ Science. $135 \quad$ (2017) 9-15. https://doi.org/10.1016/j.clay.2016.08.031.

[37] M. Lezehari, J.P. Basly, M. Baudu, O. Bouras, Alginate encapsulated pillared clays: removal of a neutralanionic biocide (pentachlorophenol) and a cationic dye (safranine) from aqueous solutions, Colloids and Surfaces A: Physicochemical and Engineering Aspects. 366 (2010) 88-94. https://doi.org/10.1016/j.colsurfa.2010.05.021.

[38] R. Ahmad, R. Kumar, Synthesis and Properties of Cellulose Carbon Encapsulated ZnO for Dye Removal, Journal of Dispersion Science and Technology. 32 (2011) 737-740. https://doi.org/10.1080/01932691.2010.480869.

[39] O. Moradi, M. Aghaie, K. Zare, M. Monajjemi, H. Aghaie, The study of adsorption characteristics $\mathrm{Cu} 2+$ and $\mathrm{Pb} 2+$ ions onto PHEMA and P(MMA-HEMA) surfaces from aqueous single solution, Journal of Hazardous Materials. 170 (2009) 673-679. https://oi.org/10.1016/j.jhazmat.2009.05.012. 
[40] A. Gil, L. Santamaría, S.A. Korili, Removal of Caffeine and Diclofenac from Aqueous Solution by Adsorption on Multiwalled Carbon Nanotubes, Colloid and Interface Science Communications. 22 (2018) 25-28. https://doi.org/10.1016/j.colcom.2017.11.007.

[41] J.V. Milojković, Z.R. Lopičić, I.P. Anastopoulos, J.T. Petrović, S.Z. Milićević, M.S. Petrović, M.D. Stojanović, Performance of aquatic weed - Waste Myriophyllum spicatum immobilized in alginate beads for the removal of $\mathrm{Pb}(\mathrm{II})$, Journal of Environmental Management. 232 (2019) 97-109. https://doi.org/10.1016/j.jenvman.2018.10.075.

[42] Z. Harrache, M. Abbas, T. Aksil, M. Trari, Thermodynamic and kinetics studies on adsorption of Indigo Carmine from aqueous solution by activated carbon, Microchemical Journal. 144 (2019) 180-189. https://doi.org/10.1016/j.microc.2018.09.004.

[43] Ravi, L.M. Pandey, Enhanced adsorption capacity of designed bentonite and alginate beads for the effective removal of methylene blue, Applied Clay Science. 169 (2019) 102111. https:/doi.org/10.1016/j.clay.2018.12.019.

[44] Rahmi, Ishmaturrahmi, I. Mustafa, Methylene blue removal from water using H2SO4 crosslinked magnetic chitosan nanocomposite beads, Microchemical Journal. 144 (2019) 397-402. https://doi.org/10.1016/j.microc.2018.09.032.

[45] X. Liu, B. Cui, S. Liu, Q. Ma, Methylene Blue Removal by Graphene Oxide/Alginate Gel Beads, Fibers Polym. 20 (2019) 1666-1672. https://doi.org/10.1007/s12221-019-9011-z.

[46] A. Nasrullah, A.H. Bhat, A. Naeem, M.H. Isa, M. Danish, High surface area mesoporous activated carbon-alginate beads for efficient removal of methylene blue, International Journal of Biological Macromolecules. $107 \quad$ (2018) 1792-1799. https://doi.org/10.1016/j.ijbiomac.2017.10.045.

[47] Q. Peng, M. Liu, J. Zheng, C. Zhou, Adsorption of dyes in aqueous solutions by chitosanhalloysite nanotubes composite hydrogel beads, Microporous and Mesoporous Materials. 201 (2015) 190-201. https://doi.org/10.1016/j.micromeso.2014.09.003. 
[48] K.W. Jung, B.H. Choi, M.J. Hwang, T.U. Jeong, K.H. Ahn, Fabrication of granular activated carbons derived from spent coffee grounds by entrapment in calcium alginate beads for adsorption of acid orange 7 and methylene blue, Bioresource Technology. 219 (2016) 185-195. https//doi.org/10.1016/j.biortech.2016.07.098.

[49] L. Liu, Y. Wan, Y. Xie, R. Zhai, B. Zhang, J. Liu, The removal of dye from aqueous solution using alginate-halloysite nanotube beads, Chemical Engineering Journal. 187 (2012) 210-216. https//doi.org/10.1016/j.cej.2012.01.136.

[50] H.W. Kwak, Y. Hong, M.E. Lee, H.J. Jin, Sericin-derived activated carbon-loaded alginate bead: An effective and recyclable natural polymer-based adsorbent for methylene blue removal, International Journal of Biological Macromolecules. 120 (2018) 906-914. https://doi.org/10.1016/j.ijbiomac.2018.08.116.

[51] Z. Anfar, A. Amedlous, A.A. El Fakir, M. Zbair, H. Ait Ahsaine, A. Jada, N. El Alem, High extent mass recovery of alginate hydrogel beads network based on immobilized biosourced porous carbon@Fe3O4-NPs for organic pollutants uptake, Chemosphere. 236 (2019) 124351. https://doi.org/10.1016/j.chemosphere.2019.124351. 


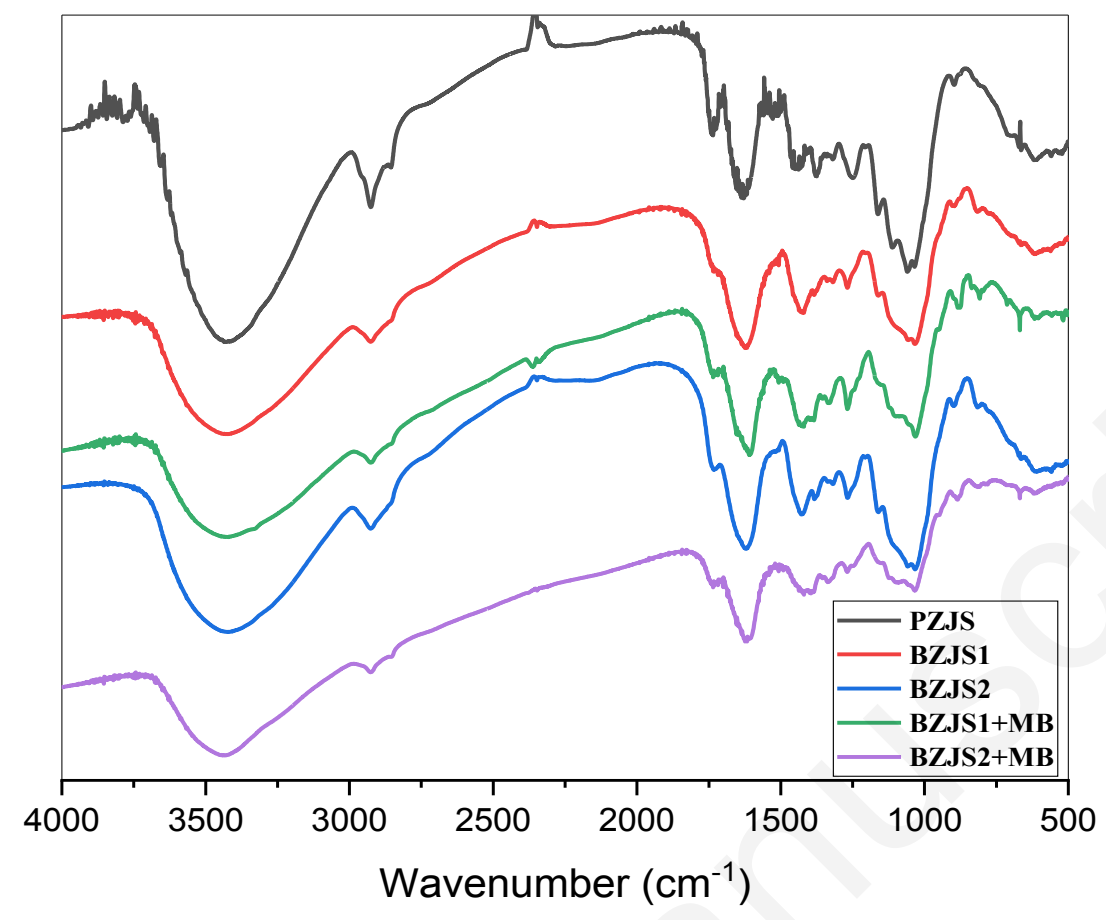

Figure 1. FTIR characterization of PZJS, BZJS1, BZJS2 and after adsorption of MB. 
Figure 2. SEM captures of PZJS (a), BZJS1 (b) and BZJS2 (c)
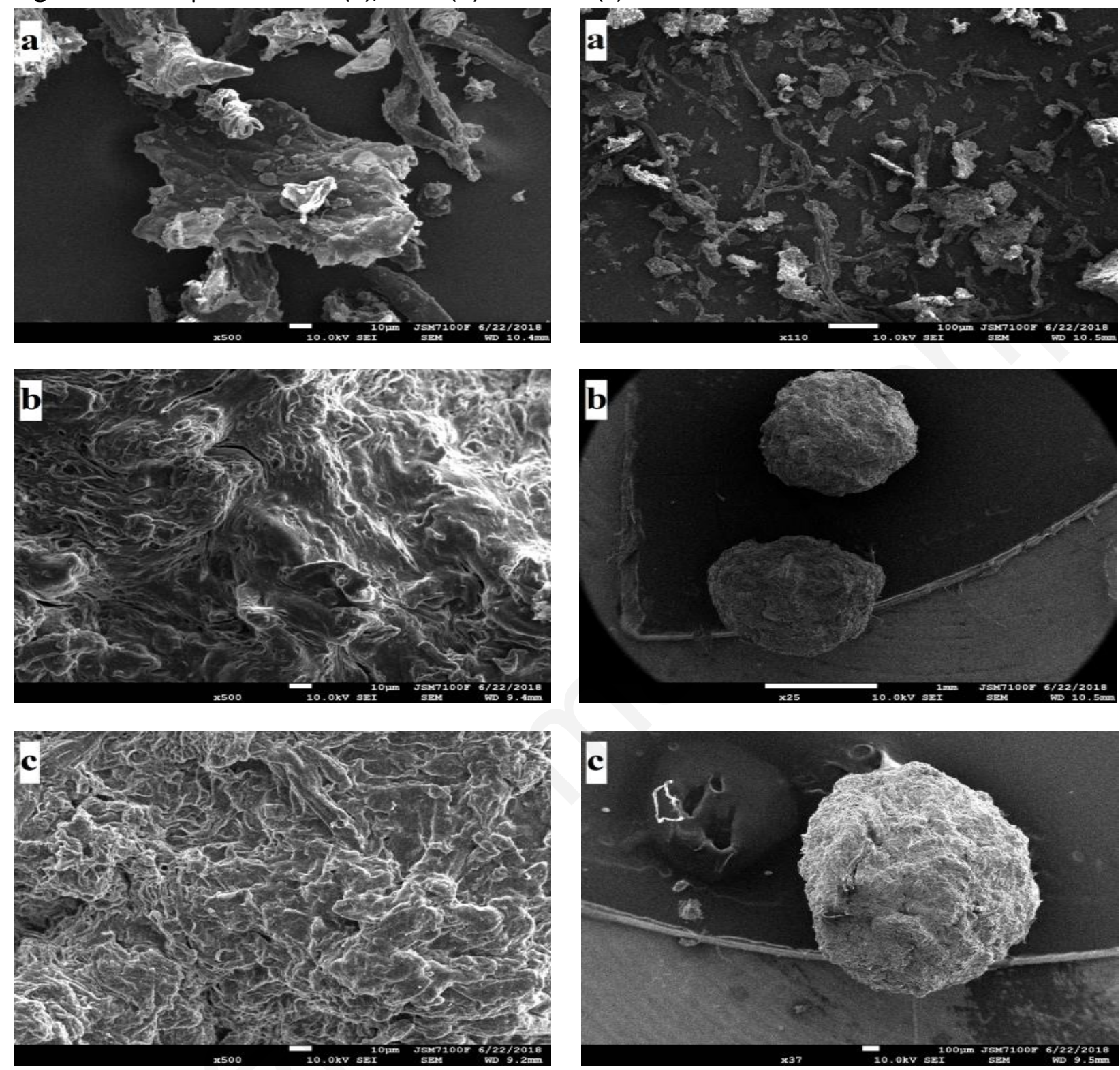

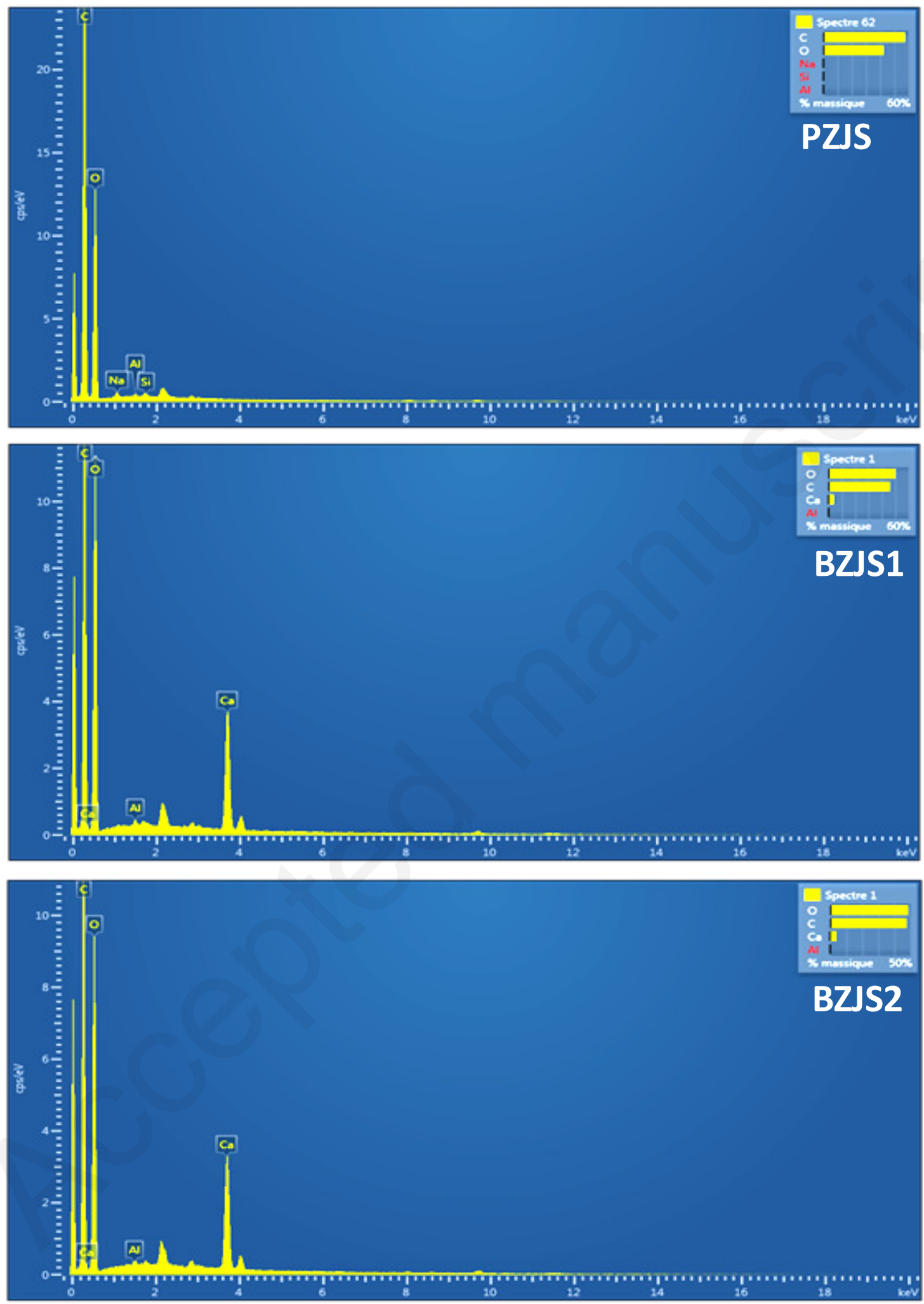

Figure 3. Elemental analysis by EDX of PZJS, BTS1and BZJS2. 


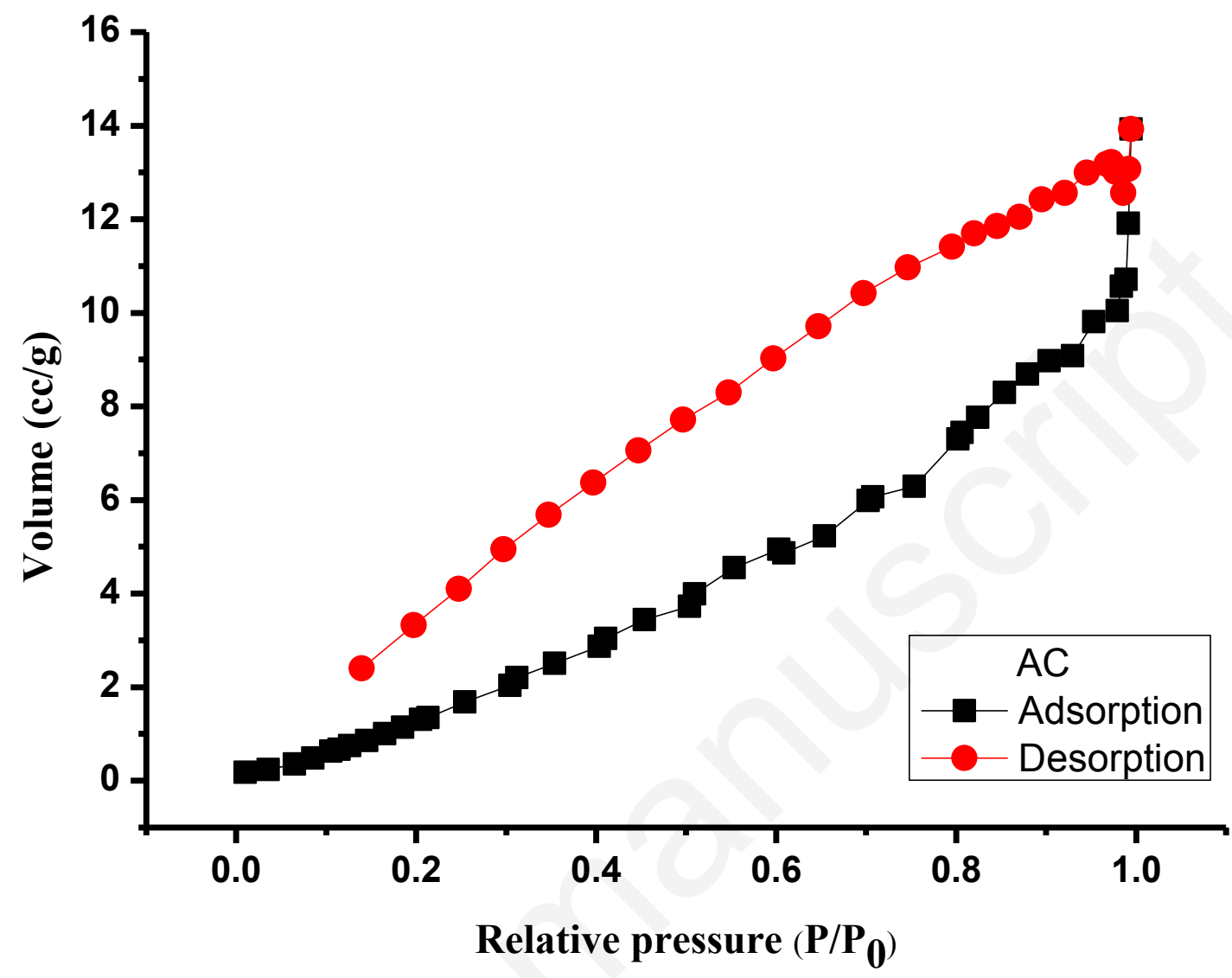

Figure 4. Nitrogen adsorption-desorption curve of the best adsorbent (BZJS1). 


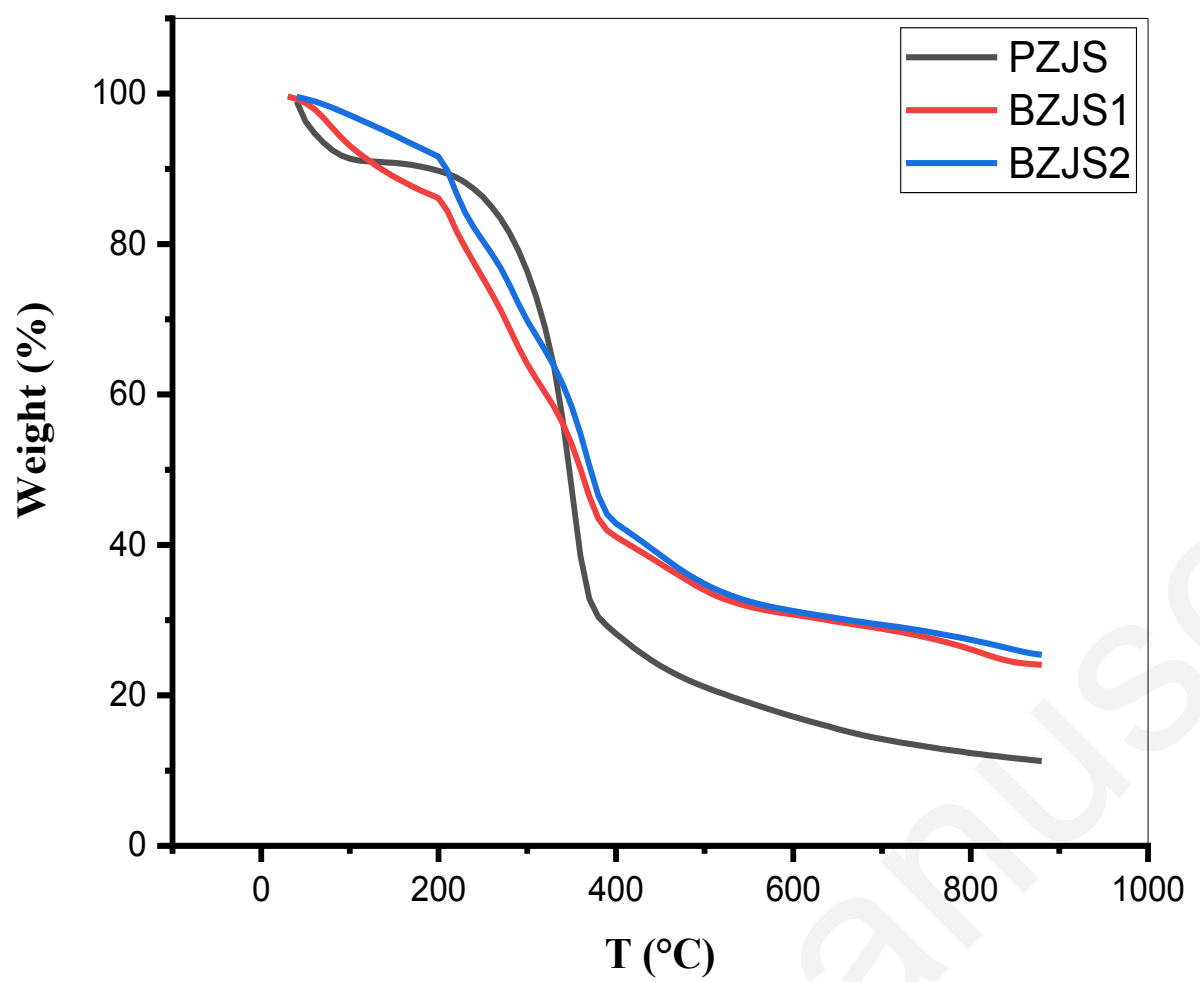

Figure 5. TG curves of PZJS, BZJS1 and BZJS2. 


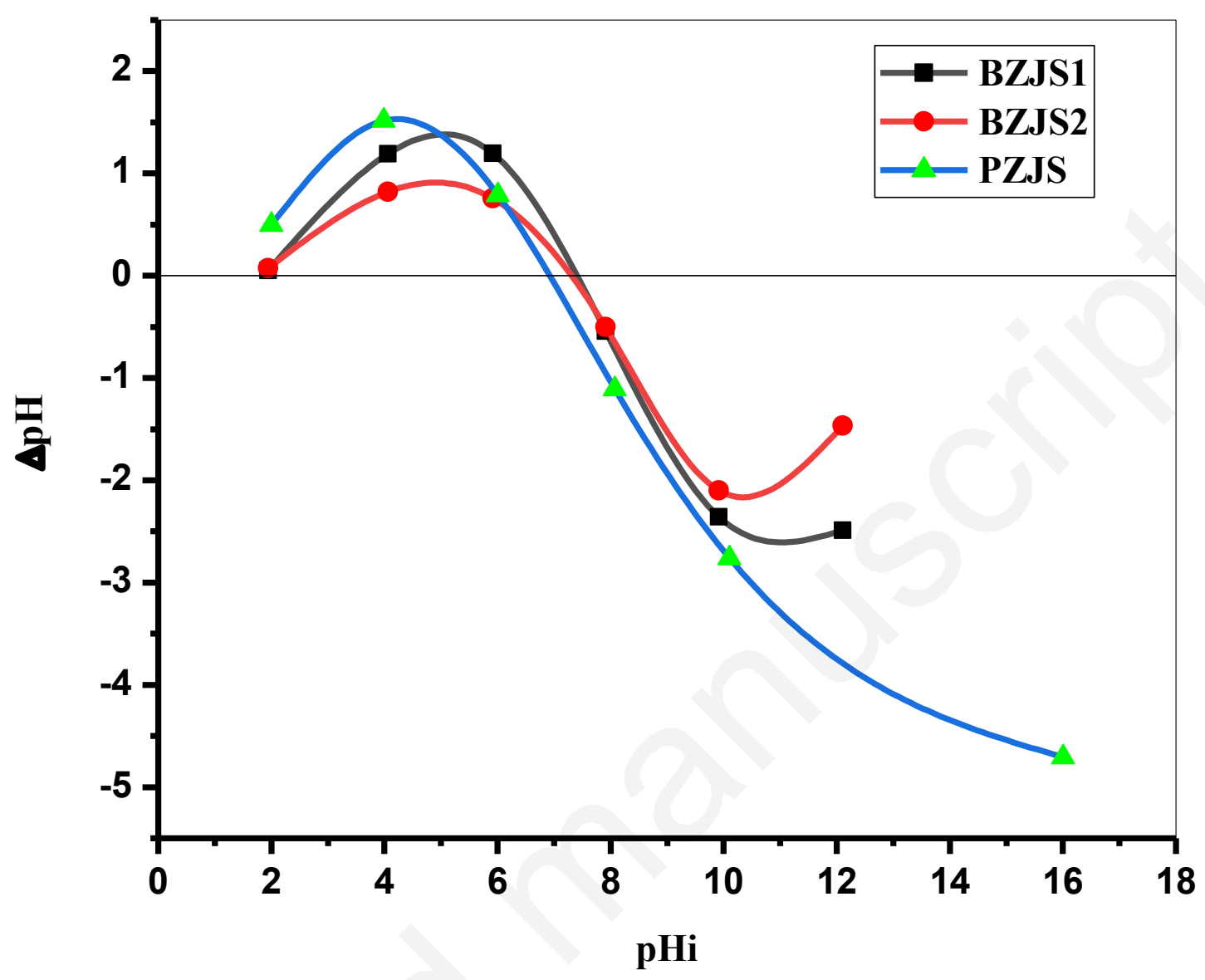

Figure 6. Isoelectric points of PZJS, BZJS1, and BZJS2. $\left(T=25^{\circ} \mathrm{C}\right.$, stirring speed $\left.=250 \mathrm{rpm}\right)$ 


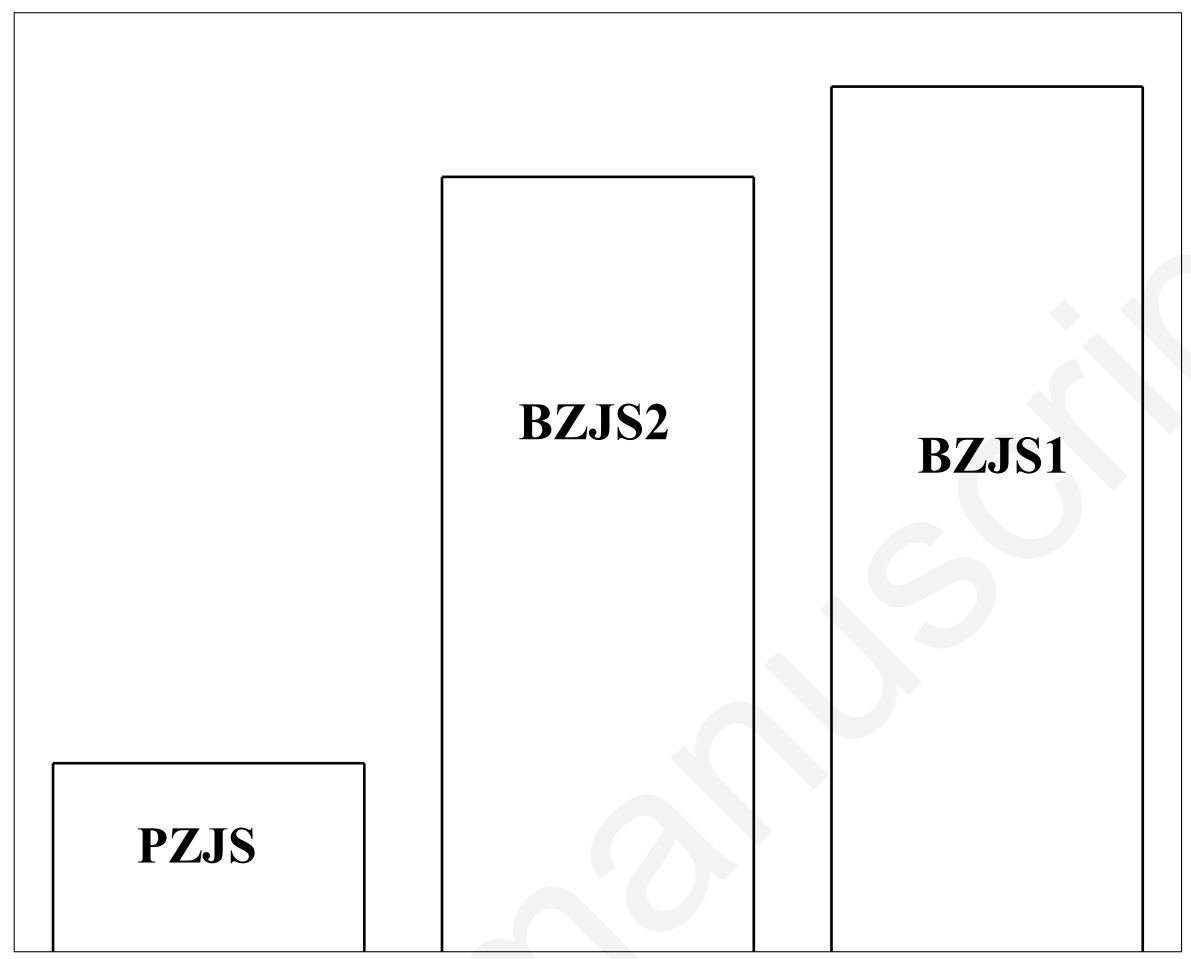

Figure 7. Encapsulation effect on the performance of the $\mathrm{MB}$ adsorption capacity. ( $\mathrm{T}=25^{\circ} \mathrm{C}$, stirring speed $=250 \mathrm{rpm}, \mathrm{pH}=6.2$ ) 

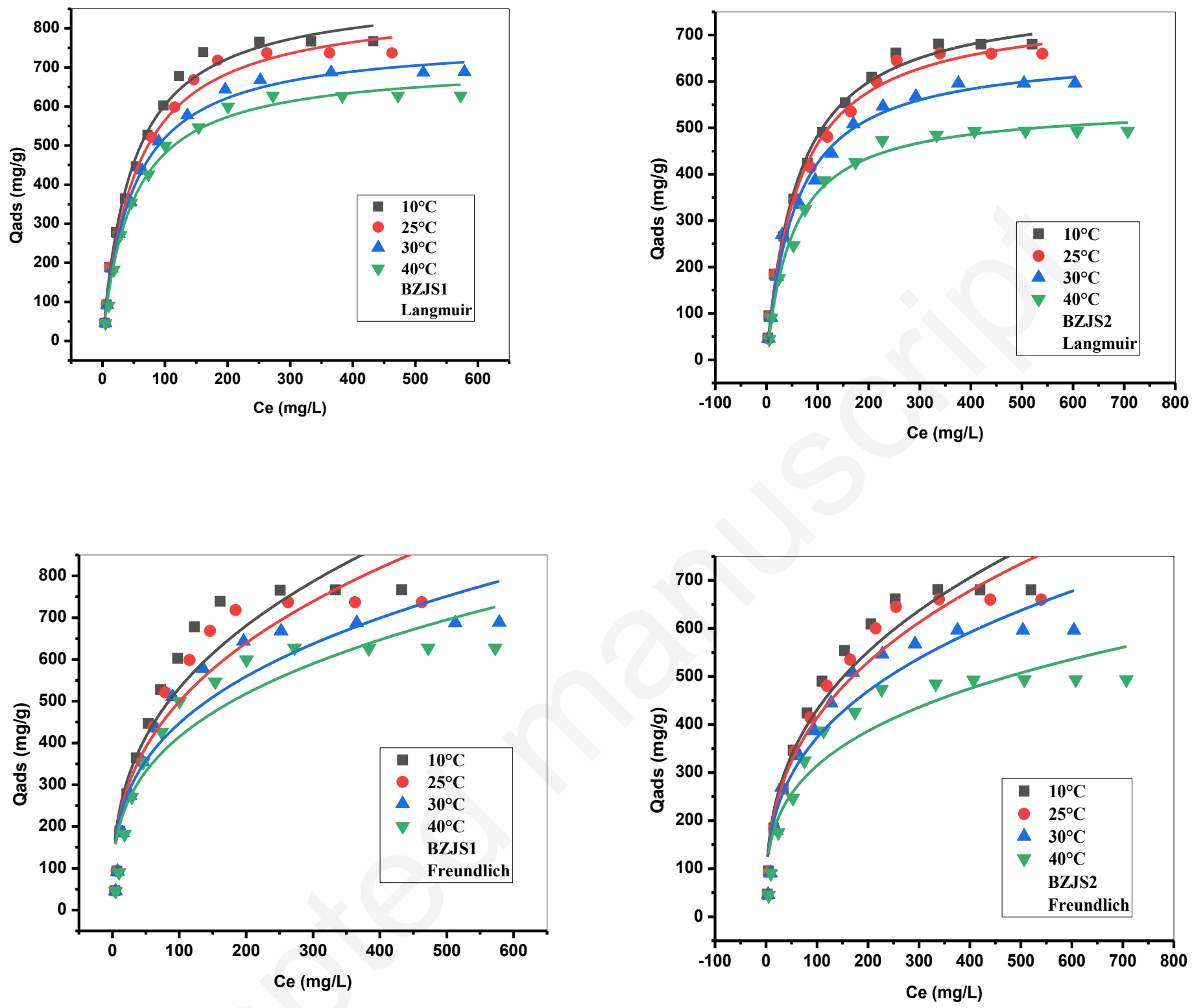

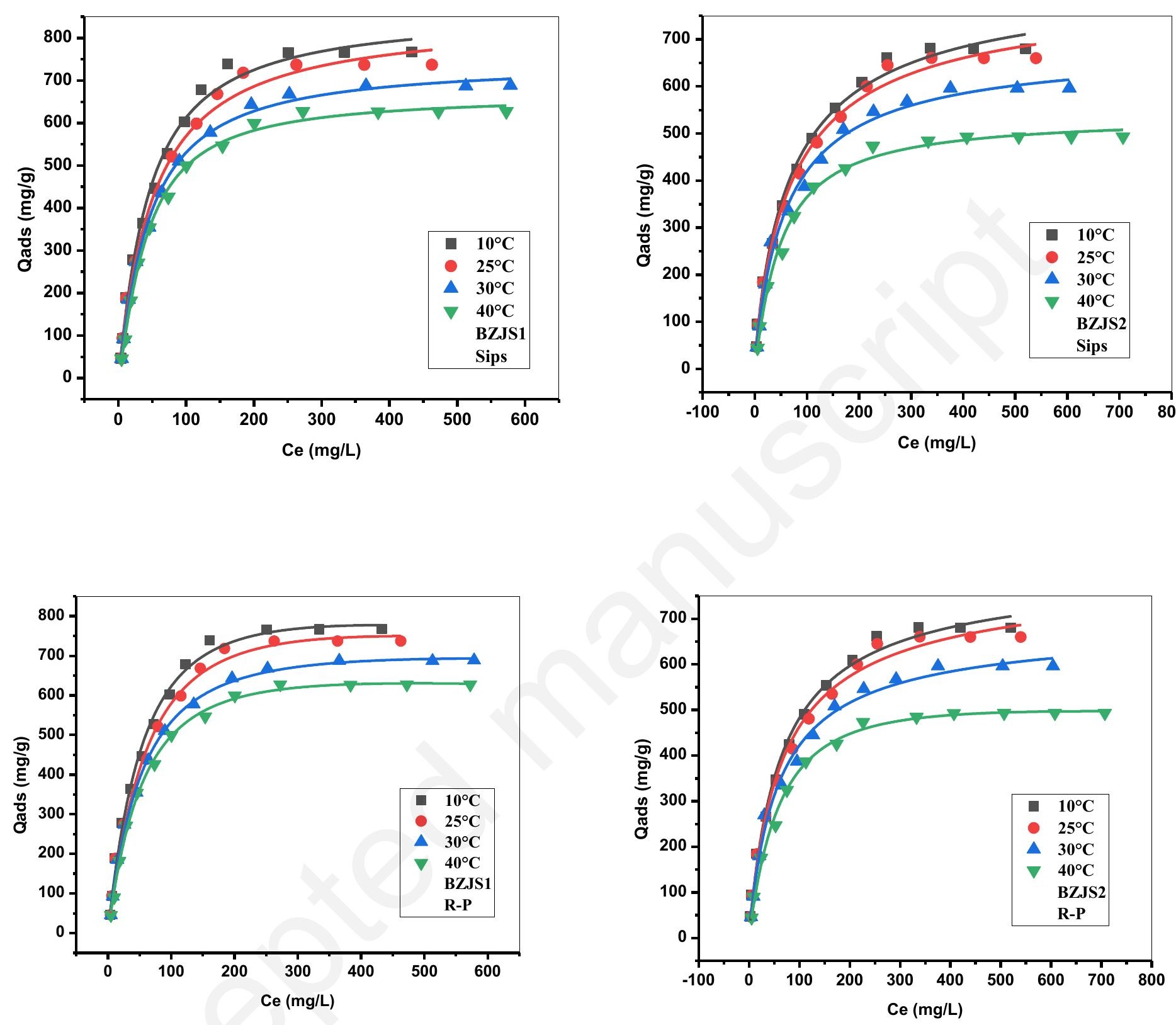

Figure 8. Experimental data (points) of MB adsorption onto BZJS1 and BZJS2. Modeling Data (lines) by Langmuir, Freundlich, Sips, and Redlich-Peterson (R-P) models at different temperatures. (stirring speed $=250 \mathrm{rpm}, \mathrm{pH}=6.2$ ) 

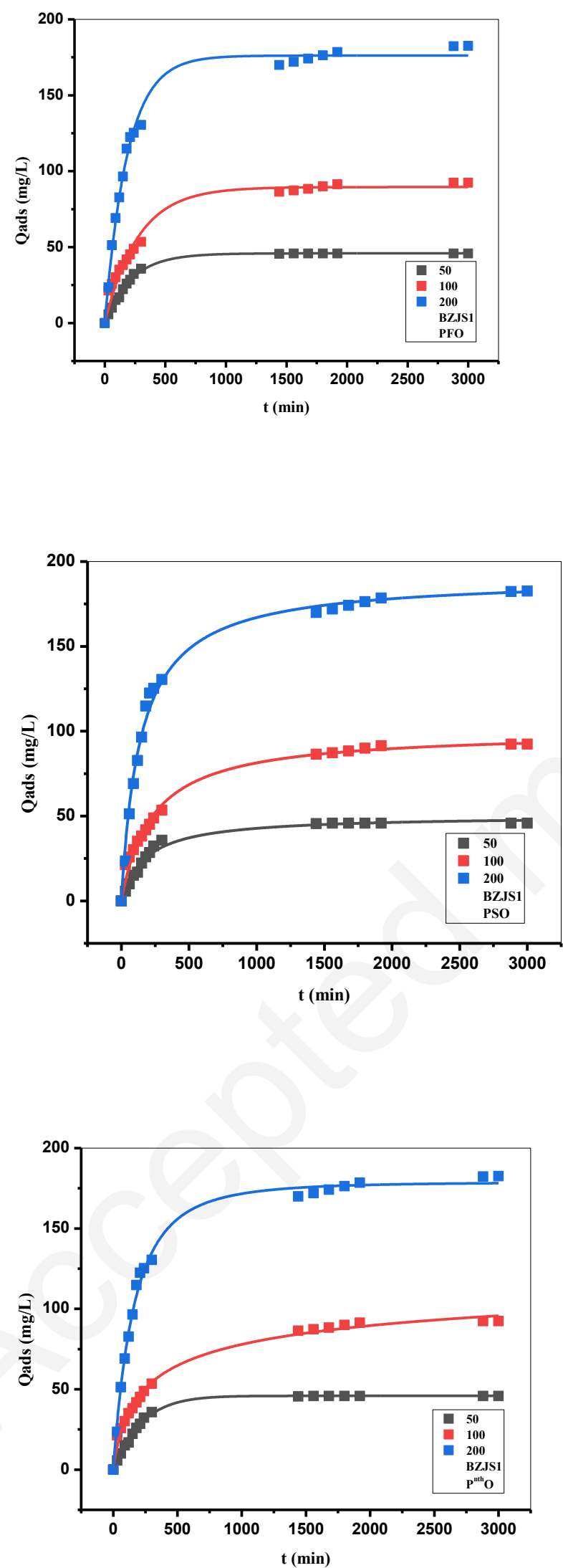
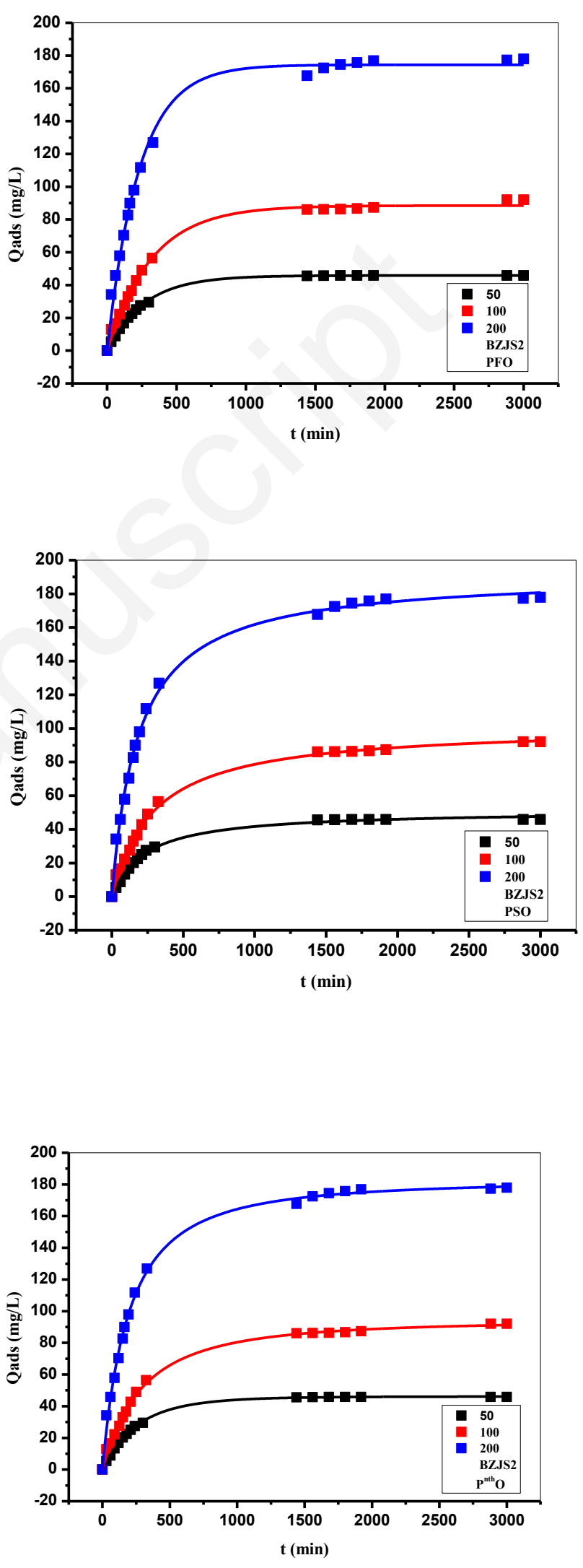
Figure 9. Kinetics data (symbol) of MB adsorption onto BZJS1 and BZJS2 and modeling data (lines) by PFO, $\mathrm{PSO}$, and $\mathrm{P}^{\text {nth }} \mathrm{O}$ with different initial concentrations. $\left(\mathrm{T}=25^{\circ} \mathrm{C}\right.$, stirring speed $\left.=250 \mathrm{rpm}, \mathrm{pH}=6.2\right)$

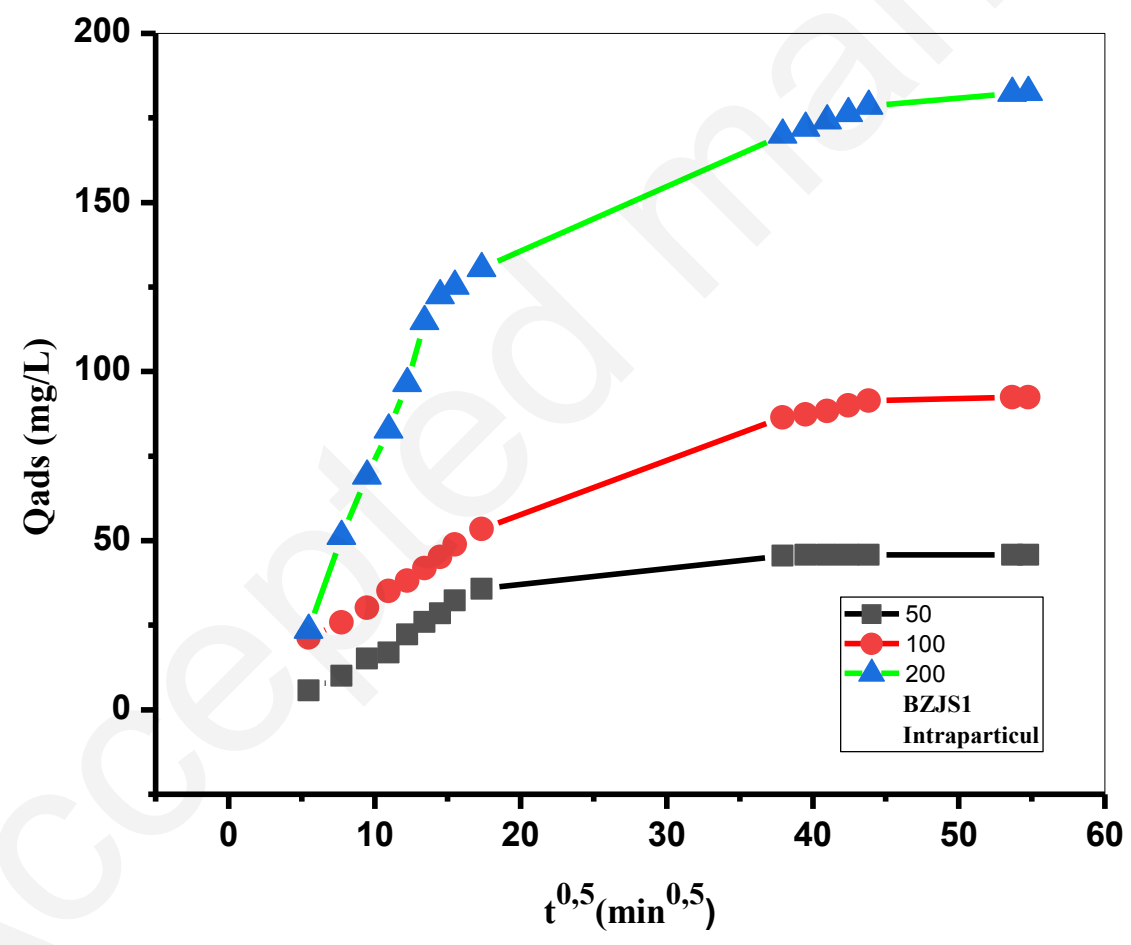




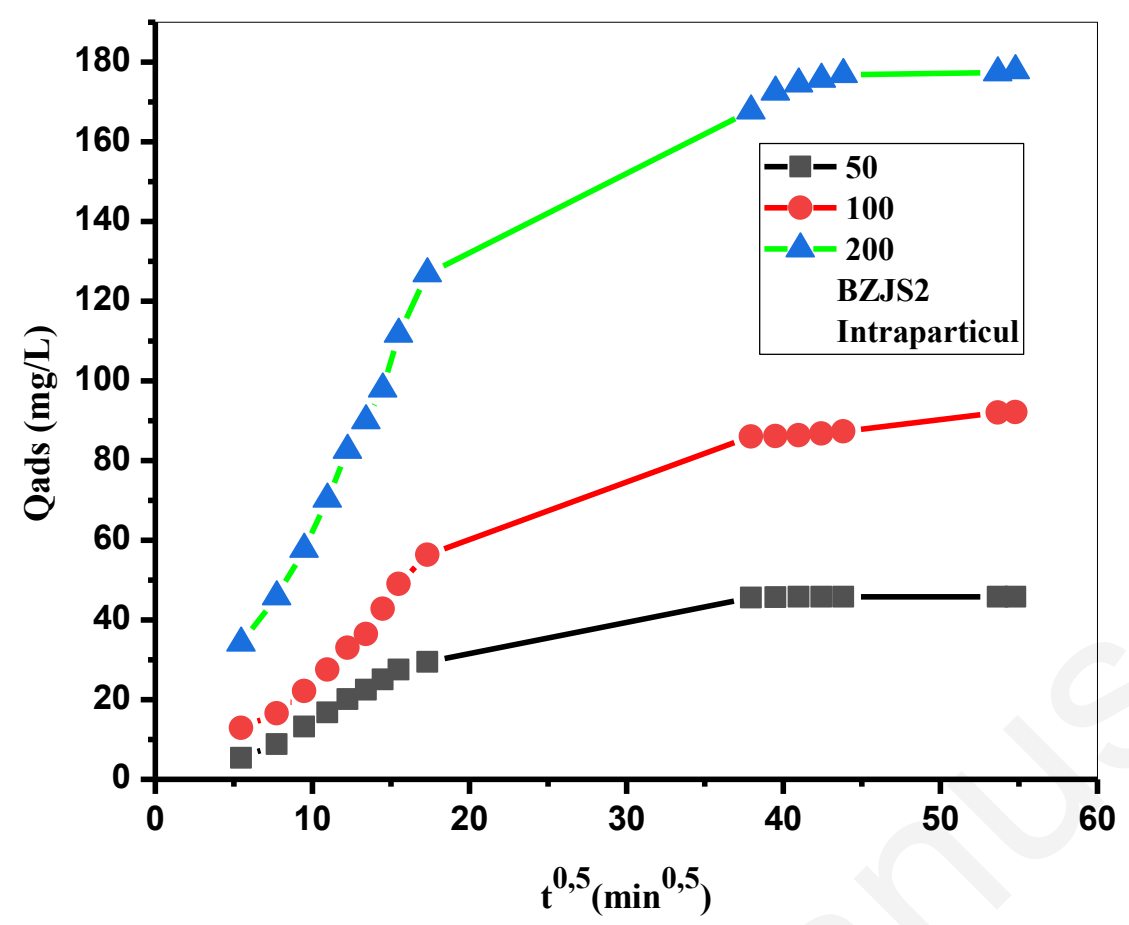

Figure 10. Intraparticle diffusion modeling of MB adsorption onto BZJS1 and BZJS2. (T=25 ${ }^{\circ} \mathrm{C}$, stirring speed $=250 \mathrm{rpm}, \mathrm{pH}=6.2$ )

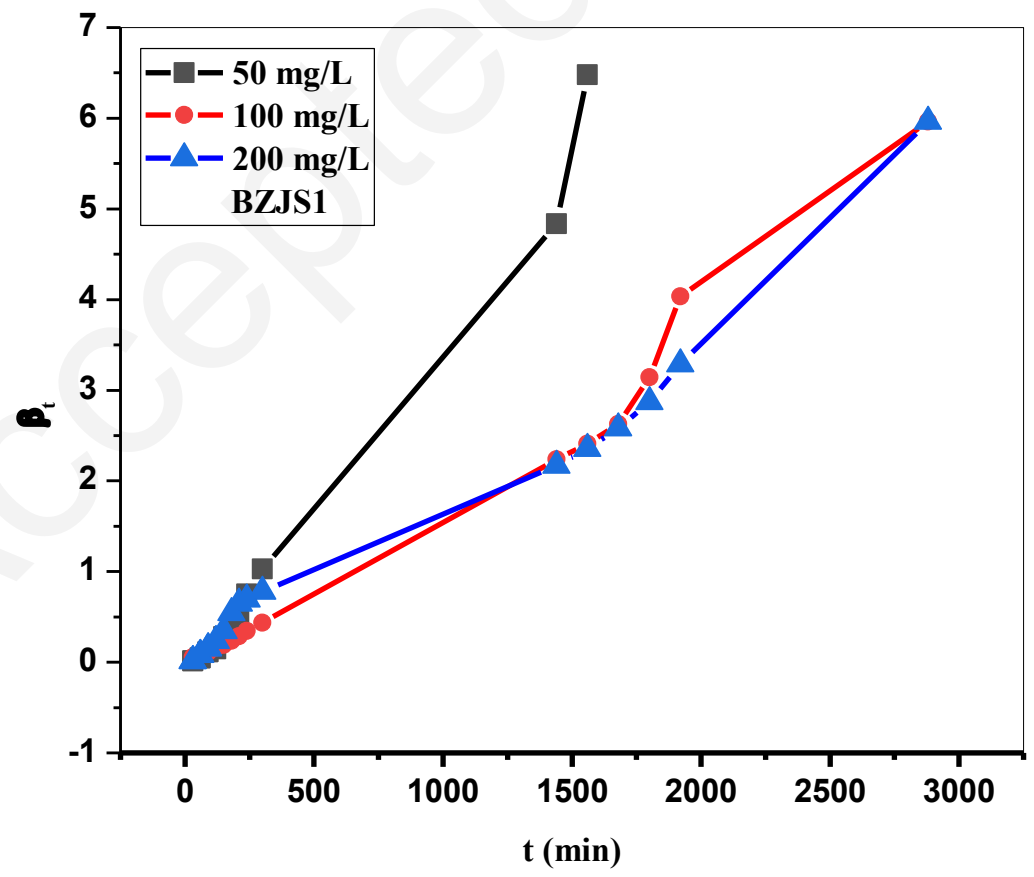




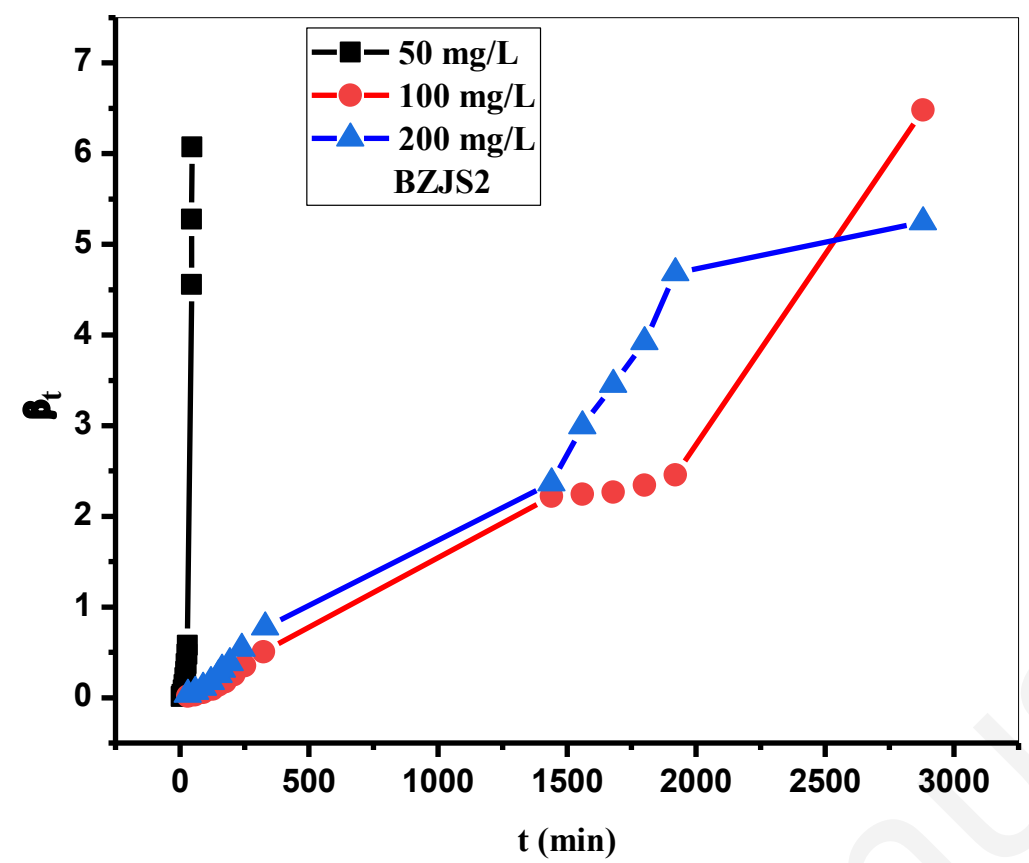

Figure 11. Boyd model data of $\mathrm{MB}$ adsorption onto BZJS1 and BZJS2. $\left(\mathrm{T}=25^{\circ} \mathrm{C}\right.$, stirring speed $=250$ rpm, $\mathrm{pH}=6.2$ ) 


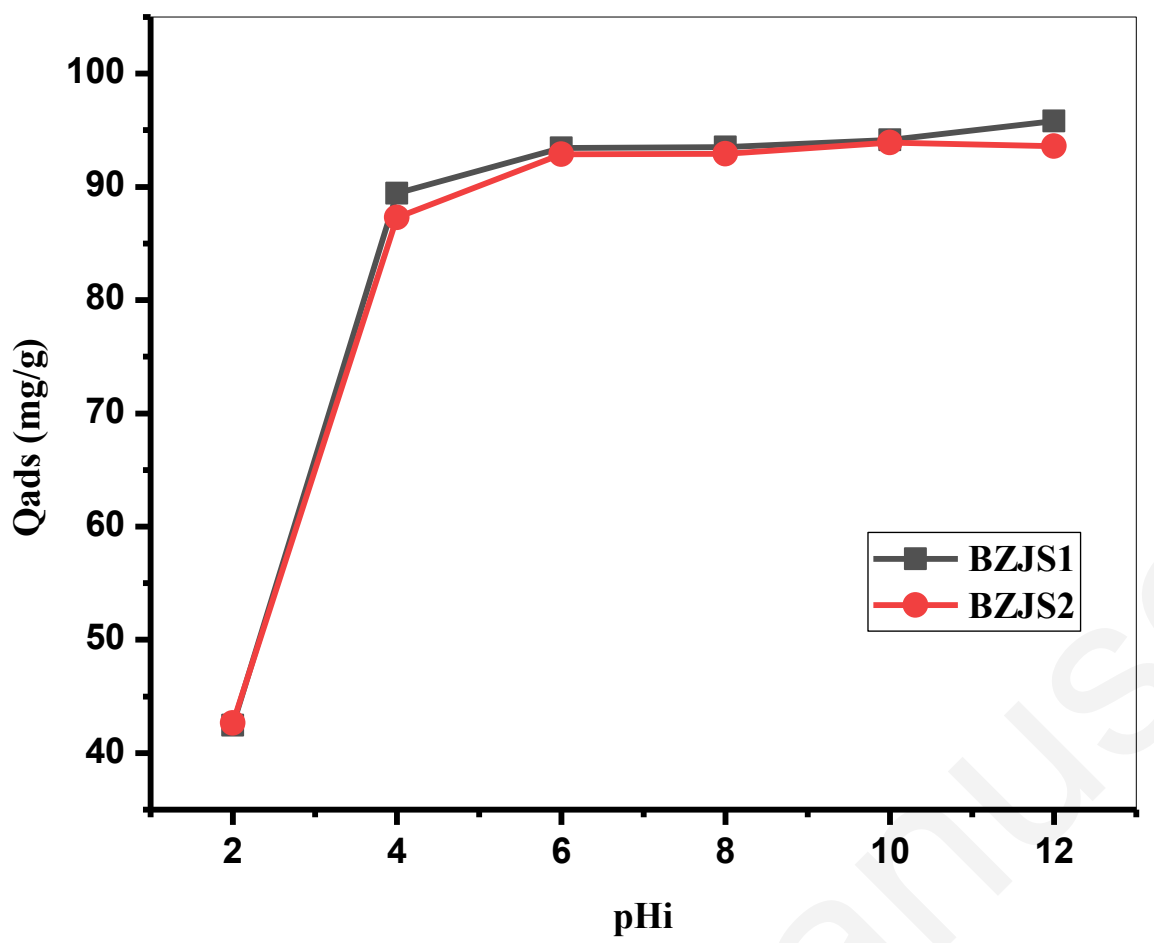

Figure 12. $\mathrm{pH}$ effect of $\mathrm{MB}$ adsorption onto BZJS1 and BZJS2. $\left(T=25^{\circ} \mathrm{C}\right.$, stirring speed $\left.=250 \mathrm{rpm}\right)$ 

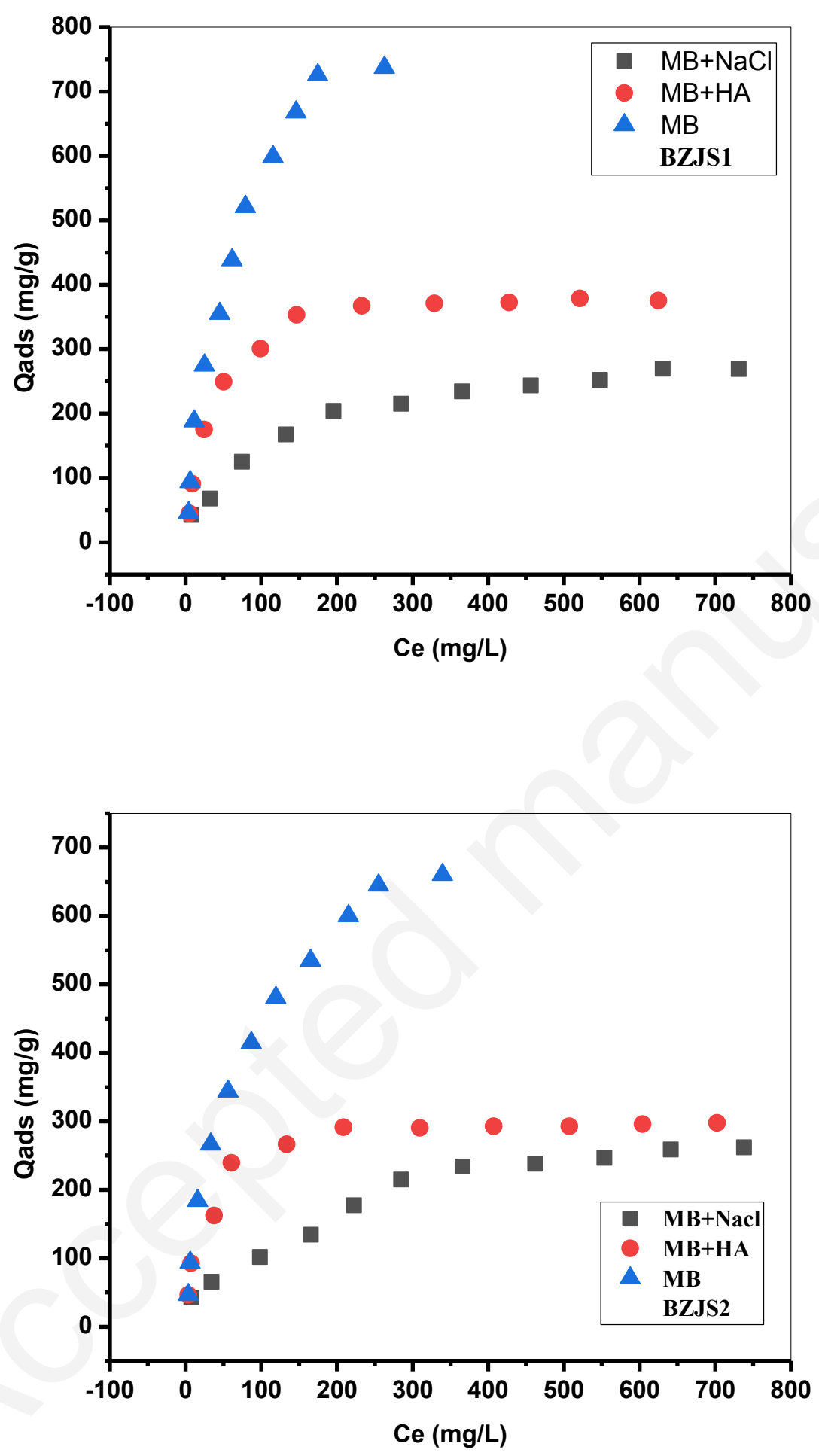

Figure 13. Ionic strength and humic acid effects on $\mathrm{MB}$ adsorption onto BZJS1 and BZJS2. $\left(\mathrm{T}=25^{\circ} \mathrm{C}\right.$, stirring speed $=250 \mathrm{rpm}, \mathrm{pH}=6.2$ ) 


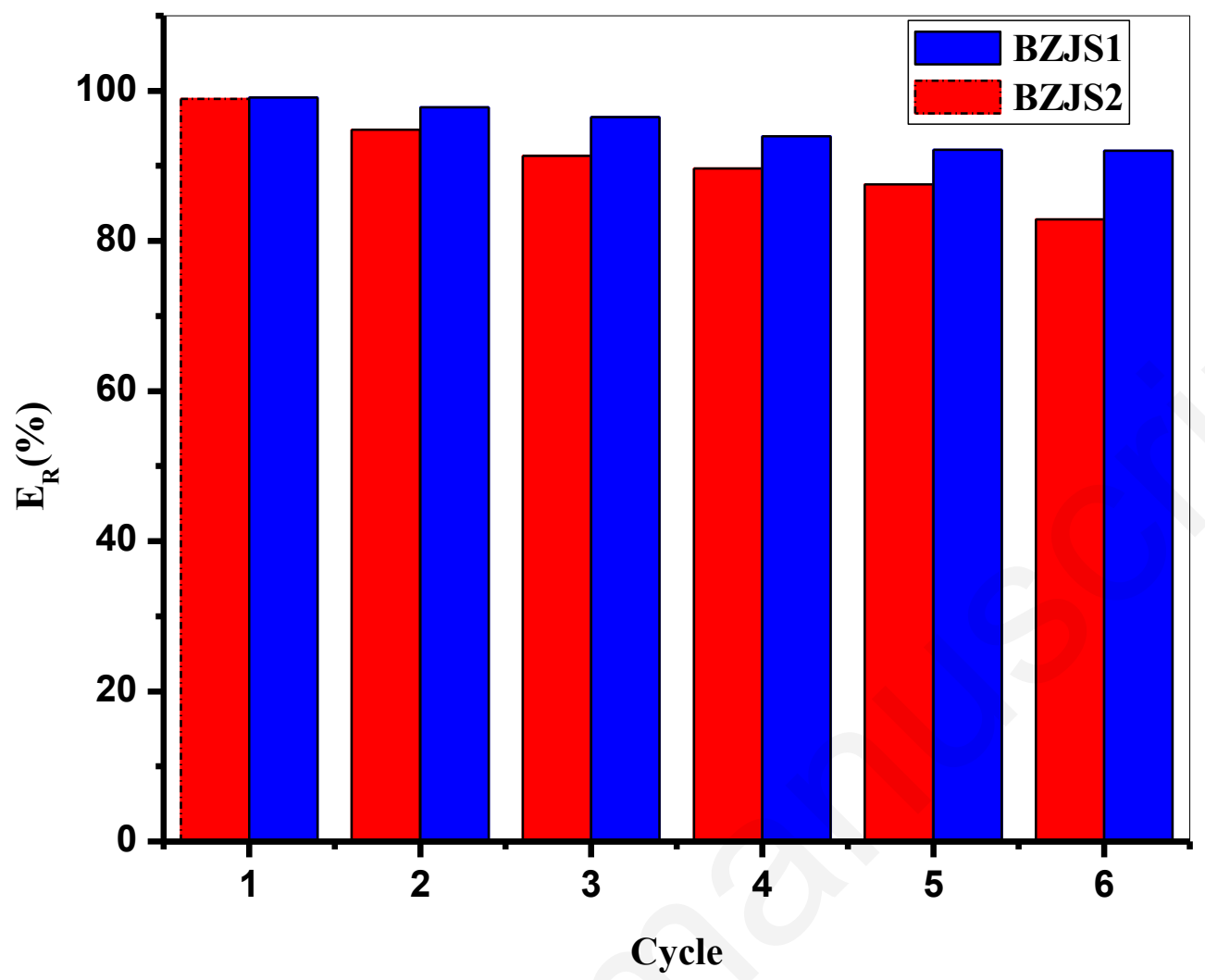

Figure 14. Regeneration study for BZJS1 and BZJS2. $\left(T=25^{\circ} \mathrm{C}\right.$, stirring speed $\left.=250 \mathrm{rpm}, \mathrm{pH}=2\right)$ 
Table 1: Some characteristics of Methylene blue (MB) dye.

\section{Methylene Blue dye (MB)}

\begin{tabular}{|c|c|}
\hline Category & Basic cationic dye \\
\hline Brute formula & $\mathrm{C}_{16} \mathrm{H}_{18} \mathrm{~N}_{3} \mathrm{SCl}$ \\
\hline Chemical name & tetramethylthionine hydrochloride \\
\hline $\begin{array}{c}\text { Molar mass (g } \\
/ \mathrm{mol})\end{array}$ & 320 \\
\hline Diametre $\left(\mathrm{A}^{\circ}\right)$ & 15 \\
\hline $\begin{array}{c}\text { Maximum } \\
\text { wavelength (nm) }\end{array}$ & 654 \\
\hline $\mathrm{pKa}$ & 3.8 \\
\hline $\begin{array}{c}\text { Solubility at } 20^{\circ} \mathrm{C} \\
(\mathrm{g} / \mathrm{L})\end{array}$ & 40 \\
\hline Structure & \\
\hline
\end{tabular}


Table 2: Description of all the used equations in this paper.

\begin{tabular}{|c|c|c|}
\hline $\begin{array}{l}\text { Equation } \\
\text { number }\end{array}$ & $\begin{array}{l}\text { Equation } \\
\text { name }\end{array}$ & Equations forme \\
\hline 01 & $\begin{array}{l}\text { Adsorbed } \\
\text { amount }\end{array}$ & $Q_{t}=\left(C_{0}-C_{t}\right) * V / m$ \\
\hline 02 & PFO & $Q_{t=} Q_{e}\left(1-e^{K_{1} t}\right)$ \\
\hline 03 & PSO & $Q_{t=}\left(\frac{K_{2} Q_{e}^{2} t}{K_{2} Q_{e} t+1}\right)$ \\
\hline 04 & $\mathbf{P}^{\text {nth }} \mathbf{O}$ & $Q_{t=} Q_{e}-\left[(n-1) K_{n} t+Q_{e}^{(1-n)}\right]^{1 /(1-n)}$ \\
\hline 05 & 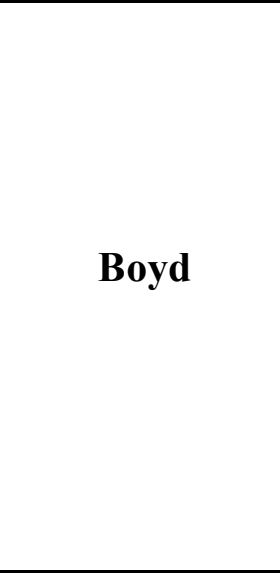 & $\begin{array}{c}F=\frac{Q_{e}}{Q_{t}}=1-\left(\frac{6}{\pi^{2}}\right) \sum_{n=1}^{\infty}\left(\frac{1}{n^{2}}\right) e^{\left(-n^{2} \beta_{t}\right)} \\
\quad \text { If } \mathrm{F}>0.85 \text { then } \\
\beta_{t}=-0.04977-\ln (1-F) \\
\text { If } \mathrm{F}<0.85 \text { then } \\
\beta_{t}=\left[\sqrt{\pi}-\sqrt{\pi-\left(\frac{\pi^{2}}{3}\right)}\right]^{2}\end{array}$ \\
\hline 06 & $\begin{array}{l}\text { Intraparticul } \\
\text { diffusion }\end{array}$ & $Q_{t=} K_{i d} t^{0.5}+A$ \\
\hline 07 & Langmuir & $\frac{Q_{e}}{Q_{m}}=\frac{K_{L} C_{e}}{1+K_{L} C_{e}}$ \\
\hline 08 & Fre undlich & $Q_{e}=K_{F} C_{e}^{1 / n_{F}}$ \\
\hline 09 & $\begin{array}{l}\text { Redlich- } \\
\text { Peterson }\end{array}$ & $Q_{e}=\frac{K_{R P} C_{e}}{\left(1+\alpha C_{e}^{\beta}\right)}$ \\
\hline 10 & Sips & $\frac{Q_{e}}{Q_{m}}=\frac{K_{S} C_{e}^{m s}}{1+K_{S} C_{e}^{m s}}$ \\
\hline 11 & Van't Hoff & $\ln \left(\frac{Q_{e}}{C_{e}} * 1000\right)=\Delta S^{\circ}-\frac{\Delta H^{\circ}}{T}$ \\
\hline 12 & $\begin{array}{c}\text { Gibbs free } \\
\text { energy change }\end{array}$ & $\Delta G^{\circ}=\Delta H^{\circ}-T * \Delta S^{\circ}$ \\
\hline 13 & $\begin{array}{c}\text { Regeneration } \\
\text { efficiency }\end{array}$ & $E_{R}=\frac{Q_{\text {des }}}{Q_{a d s}} * 100$ \\
\hline
\end{tabular}


Table 3: Elemental analysis by XRF of PZJS, BTS1and BZJS2.

\begin{tabular}{|c|c|c|c|}
\hline Adsorbent & PZJS & BZJS1 & BZJS2 \\
\hline Element & \% Weight & $\%$ Weight & $\%$ Weight \\
\hline $\mathrm{C}$ & 47.5 & 41.6 & 40.6 \\
\hline $\mathrm{O}$ & 51.7 & 52.8 & 54.3 \\
\hline $\mathrm{Ca}$ & 0.05 & 5.19 & 4.73 \\
\hline $\mathrm{Si}$ & 0.15 & 0.08 & 0.12 \\
\hline $\mathrm{Al}$ & 0.11 & 0.03 & 0.03 \\
\hline $\mathrm{P}$ & 0.03 & 0.02 & 0.01 \\
\hline $\mathrm{Zn}$ & 0.11 & 0.08 & 0.08 \\
\hline Others & 0.54 & 0.19 & 0.13 \\
\hline Total & 100.00 & 100.00 & 100.00 \\
\hline
\end{tabular}


Table 4: Textural properties of BZJS1 from $\mathrm{N}_{2}$ adsorption-desorption isotherm.

\begin{tabular}{cccc}
\hline Material & $\begin{array}{c}\text { BET surface } \\
\text { area }\left(\mathbf{m}^{\mathbf{2}} / \mathbf{g}\right)\end{array}$ & $\begin{array}{c}\text { Totale pores } \\
\text { volume } \\
\left(\mathbf{c m}^{3} / \mathbf{g}\right)\end{array}$ & $\begin{array}{c}\text { Pore diameter } \\
(\mathbf{n m})\end{array}$ \\
\hline BZJS1 & 15.68 & 0.032 & 4.11 \\
\hline
\end{tabular}


Table 5: Isotherm modeling parameters of Langmuir, Freundlich, Sips and Redlich-Peterson models for MB adsorption onto BZJS1 and BZJS2 at different temperatures.

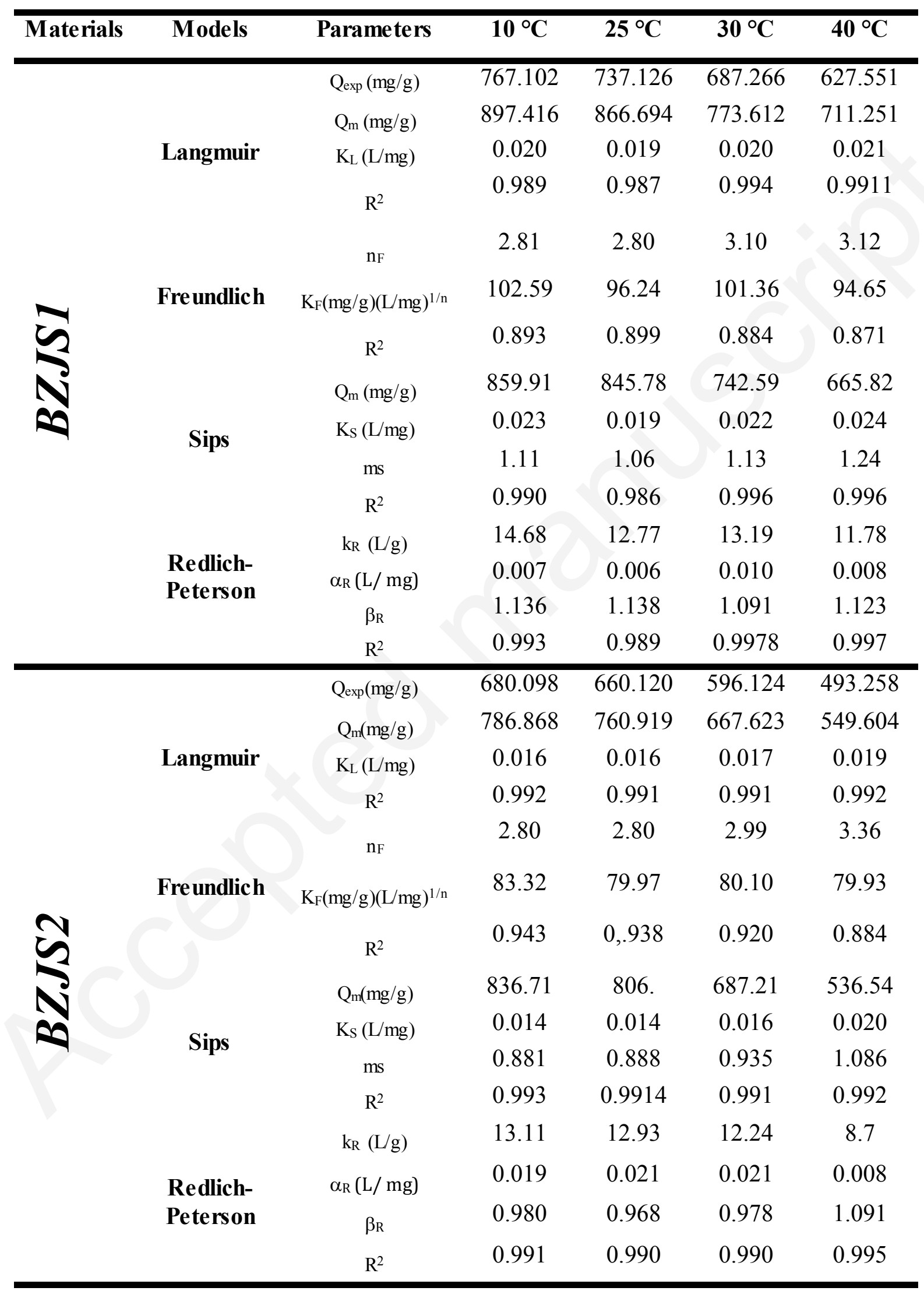


Table 6: kinetics modeling parameters of PFO, PSO and $\mathrm{P}^{\text {nth }} \mathrm{O}$ models for $\mathrm{MB}$ adsorption onto BZJS1 and BZJS2.

\begin{tabular}{|c|c|c|c|c|c|}
\hline Materials & Models & Parameters & $50 \mathrm{mg} / \mathrm{L}$ & 100 mg/L & $200 \mathrm{mg} / \mathrm{L}$ \\
\hline & \multirow{4}{*}{ PFO } & Qexp (mg/g) & 45.80 & 92.36 & 182.59 \\
\hline & & $\mathrm{Qe}(\mathrm{mg} / \mathrm{g})$ & 45.89 & 89.56 & 176.16 \\
\hline & & $\mathrm{K}_{1},\left(\min ^{-1}\right)$ & 0.004 & 0.004 & 0.005 \\
\hline & & $\mathrm{R}^{2}$ & 0.997 & 0.976 & 0.994 \\
\hline & \multirow{3}{*}{ PSO } & Qe $(\mathrm{mg} / \mathrm{g})$ & 50.37 & 100.10 & 190.77 \\
\hline & & $\begin{array}{c}\mathrm{K}_{2} * 10^{+4}(\mathrm{~g} / \\
\left.\left(\mathrm{mg}^{*} \mathrm{~min}\right)\right)\end{array}$ & 1.117 & 0.433 & 0.368 \\
\hline & & $\mathrm{R}^{2}$ & 0.984 & 0.988 & 0.992 \\
\hline & \multirow{4}{*}{$P^{n t h} O$} & $\mathrm{Qe}(\mathrm{mg} / \mathrm{g})$ & 45.88 & 156.66 & 178.88 \\
\hline & & $\mathrm{k}_{\mathrm{n},}(\mathrm{mg} / \mathrm{g})^{1-\mathrm{n} / \mathrm{min}}$ & 0.006 & $3.471 * 10^{-12}$ & $9.024 * 10^{-4}$ \\
\hline & & $\mathrm{n}$ & 0.92 & 5.12 & 1.37 \\
\hline & & $\mathrm{R}^{2}$ & 0.997 & 0.992 & 0.995 \\
\hline \multirow{11}{*}{ 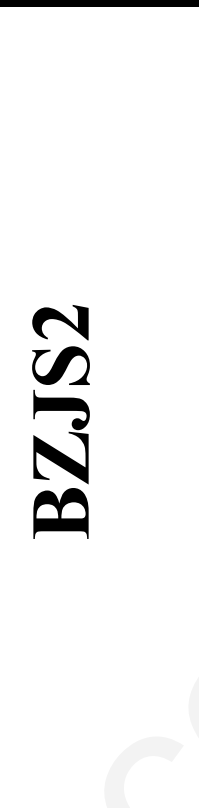 } & \multirow{4}{*}{ PFO } & Qexp (mg/g) & 45.86 & 92.10 & 177.88 \\
\hline & & Qe $(\mathrm{mg} / \mathrm{g})$ & 45.83 & 88.49 & 174.37 \\
\hline & & $\mathrm{K}_{1,(1 / \mathrm{min})}$ & 0.004 & 0.003 & 0.004 \\
\hline & & $\mathrm{R}^{2}$ & 0.999 & 0.996 & 0.994 \\
\hline & \multirow{4}{*}{ PSO } & Qe (mg/g) & 51.33 & 101.67 & 191.93 \\
\hline & & $\begin{array}{r}\mathrm{K}_{2} * 10^{+4}(\mathrm{~g} \\
(\mathrm{mg} * \min ))\end{array}$ & 0.843 & 0.336 & 0.280 \\
\hline & & $\mathrm{R}^{2}$ & 0.996 & 0.997 & 0.997 \\
\hline & & Qe (mg/g) & 46.115 & 94.250 & 182.796 \\
\hline & \multirow{3}{*}{$P^{n \text {th }} O$} & $\mathrm{k}_{\mathrm{n}},(\mathrm{mg} / \mathrm{g})^{1-\mathrm{n} / \mathrm{min}}$ & 0.002 & $2.800^{*} 10^{-4}$ & $1.969 * 10^{-4}$ \\
\hline & & $\mathrm{n}$ & 1.137 & 1.549 & 1.626 \\
\hline & & $\mathrm{R}^{2}$ & 0.999 & 0.997 & 0.997 \\
\hline
\end{tabular}


Table 7: Thermodynamic parameters of MB adsorption onto BZJS1 and BZJS2.

\begin{tabular}{ccccc}
\hline Adsorbent & $\mathbf{T}\left({ }^{\circ} \mathbf{K}\right)$ & $\Delta \mathbf{G}^{\circ}(\mathbf{K J} / \mathbf{m o l})$ & $\Delta \mathbf{H}^{\circ}(\mathbf{K J} / \mathbf{m o l})$ & $\Delta \mathbf{S}^{\circ}\left(\mathbf{J} / \mathbf{m o l}{ }^{*} \mathbf{K}\right)$ \\
\hline \multirow{2}{*}{ BZJS1 } & 283 & -17.708 & & \\
& 298 & -18.023 & -11.655 & 21.389 \\
& 303 & -18.136 & & \\
& 313 & -18.350 & & \\
\hline \multirow{3}{*}{ BZJS2 } & 283 & -17.096 & & \\
& 298 & -17.217 & -14.813 & \\
& 303 & -17.257 & & \\
& 313 & -17.340 & & \\
\hline
\end{tabular}


Table 8: MB adsorption onto various beads with different precursors.

\begin{tabular}{|c|c|c|c|c|}
\hline Precursor & $\begin{array}{l}\text { Encapsulating } \\
\text { agent }\end{array}$ & $\begin{array}{l}\text { Adsorbed } \\
\text { amount }\end{array}$ & $\begin{array}{l}\text { Regeneratio } \\
\text { n cycle }\end{array}$ & Reference \\
\hline Bentonite & Sodium alginate & 2024 & More than 2 & {$[42]$} \\
\hline Fe3O4 particle & Chitosan & 20.40 & -- & {$[43]$} \\
\hline graphene oxide & Sodium alginate & 357.14 & 5 & {$[44]$} \\
\hline $\begin{array}{l}\text { Activated carbon from } \\
\text { Mangosteen fruit peel }\end{array}$ & sodium alginate & 230 & -- & {$[45]$} \\
\hline Halloysite & Chitosan & 270.27 & 5 & [46] \\
\hline $\begin{array}{l}\text { Activated carbon from } \\
\text { spent coffee grounds }\end{array}$ & sodium alginate & 710.2 & 7 & {$[47]$} \\
\hline Halloysite nanotube & sodium alginate & 250.0 & 10 & {$[48]$} \\
\hline $\begin{array}{c}\text { Activated carbon from } \\
\text { silk sericin }\end{array}$ & sodium alginate & 502.5 & 5 & [49] \\
\hline $\mathrm{PC} @ \mathrm{Fe}_{3} \mathrm{O}_{4} \mathrm{NPs}$ & sodium alginate & 49.66 & -- & {$[50]$} \\
\hline $\begin{array}{c}\text { Ziziphus jujuba stones } \\
\text { (BZJS1) }\end{array}$ & Sodium alginate & 737.13 & 6 & This study \\
\hline $\begin{array}{l}\text { Ziziphus jujuba stones } \\
\text { (BZJS2) }\end{array}$ & Sodium alginate & 660.12 & 6 & This study \\
\hline
\end{tabular}

